\title{
Perdigão 2015: methodology for atmospheric multi-Doppler lidar experiments
}

\author{
Nikola Vasiljević ${ }^{1}$, José M. L. M. Palma ${ }^{2}$, Nikolas Angelou ${ }^{1}$, José Carlos Matos ${ }^{3}$, Robert Menke ${ }^{1}$, Guillaume Lea ${ }^{1}$, \\ Jakob Mann ${ }^{1}$, Michael Courtney ${ }^{1}$, Luis Frölen Ribeiro ${ }^{3,4}$, and Vitor M. M. G. C. Gomes ${ }^{2}$ \\ ${ }^{1}$ DTU Wind Energy, Technical University of Denmark, Frederiksborgvej 399, Building 118-VEA, 4000 Roskilde, Denmark \\ ${ }^{2}$ Faculty of Engineering of the University of Porto, Rua Dr. Roberto Frias, 4200-465 Porto, Portugal \\ ${ }^{3}$ Institute of Science and Innovation in Mechanical and Industrial Engineering, Rua Dr. Roberto Frias, \\ 4200-465 Porto, Portugal \\ ${ }^{4}$ Polytechnic Institute of Bragança, Campus de Santa Apolónia, 5300-253 Bragança, Portugal
}

Correspondence to: Nikola Vasiljević (niva@dtu.dk)

Received: 20 January 2017 - Discussion started: 15 February 2017

Revised: 2 August 2017 - Accepted: 4 August 2017 - Published: 21 September 2017

\begin{abstract}
The long-range and short-range WindScanner systems (LRWS and SRWS), multi-Doppler lidar instruments, when combined together can map the turbulent flow around a wind turbine and at the same time measure mean flow conditions over an entire region such as a wind farm. As the WindScanner technology is novel, performing field campaigns with the WindScanner systems requires a methodology that will maximize the benefits of conducting WindScannerbased experiments. Such a methodology, made up of 10 steps, is presented and discussed through its application in a pilot experiment that took place in a complex and forested site in Portugal, where for the first time the two WindScanner systems operated simultaneously. Overall, this resulted in a detailed site selection criteria, a well-thought-out experiment layout, novel flow mapping methods and high-quality flow observations, all of which are presented in this paper.
\end{abstract}

\section{Introduction}

In wind energy research, field experiments are important for wind resource evaluation but also to establish, validate and improve theories and wind flow models. If experiments are well planned, designed, executed and reported, the field datasets have a long lifetime and are a firm basis for the advancement of our knowledge on atmospheric flows.

A large number of field experiments addressing flows over hills (see Taylor et al., 1987) were carried out between 1979 and 1986. These field experiments provided the experimental validation of the models of the wind industry resource assessment (Jackson and Hunt, 1975; Mortensen et al., 2004; Walmsley et al., 1986). Among the field experiments of the past, the Askervein hill experiment (Taylor and Teunissen, 1987; Walmsley and Taylor, 1996) is an example of a field campaign dataset that has been in use for more than 30 years. The increased computational power and developments in both numerical techniques and implementation of the flow physics have enabled the use of computational fluid dynamics (CFD) and mesoscale models at a larger scale, which calls for validation with new field experiments. The need for new and higher quality field datasets, recognized in various windenergy-related forums (e.g., EWEA, 2005, 2008; Shaw et al., 2009; van Kuik et al., 2016), is driven by the increasing size of the modern wind turbines often located in complex orographies.

Due to the costs of tall meteorological masts, especially in complex terrain, it is unrealistic to sample the wind within an entire region occupied by today's largest wind turbines or farms with traditional anemometry. This is exactly what can be achieved with multi-Doppler lidar systems. The reason for using multiple lidars is that a single lidar can directly sense only line of sight (LOS) or radial wind speed, which is a projection of the wind vector on a laser light propagation path (see Cariou and Boquet, 2011). Indirectly, by employing single-Doppler retrieval techniques (e.g., Browning and Wexler, 1968; Strauch et al., 1987) on a number of LOS 
measurements, single lidars can retrieve accurate wind vector information if the flow is horizontally homogeneous (see Courtney et al., 2008; Peña Diaz et al., 2009). In complex terrain, the flow rarely satisfies this assumption, which leads to erroneous retrievals of the wind vector by single lidars (Bingöl et al., 2009).

Employing at least two lidars and intersecting their beams at a point of interest is required to directly measure two components of the wind at that point, while to fully characterize the wind vector at least three laser beams should intersect at a given point. By moving the beam intersection over an area or volume of interest, the flow can be mapped and resolved in two or all three dimensions. Dual-Doppler setups consisting of two scanning lidars have been used in several large atmospheric studies (e.g., McCarthy et al., 1982; Newsom et al., 2005; Collier et al., 2005; Grubišić et al., 2008), while their application in wind-energy-related studies is rather recent (e.g., Iungo et al., 2013; Newsom et al., 2015). Triplelidars were primarily used to demonstrate the capability of accurately retrieving the wind vector in a single point (Mann et al., 2009) or in multiple points distributed along a single vertical axis (see virtual masts in Fuertes et al., 2014; Newman et al., 2016; Lundquist et al., 2017).

As discussed in Vasiljević et al. (2016a), lidars in the previously mentioned studies were individually configured, run and monitored; thus, there was no central computer that would ensure their synchronicity. Also, commercially available lidars were used in the majority of these studies, and the configuration flexibility and available auxiliary information of such devices is usually limited (e.g., no accurate timing of scans and only simple scanning methods are available).

Efforts put into the WindScanner.dk project have resulted in two specific and highly configurable multi-Doppler lidar instruments, known as the long-range and short-range WindScanner systems (LRWS and SRWS; Mikkelsen, 2014), specifically designed to address the aforementioned needs of wind energy research for new measurements. These instruments unlocked the potentials not only to measure the wind field at a single point located within the rotor-swept area but also to map entire wind fields within the volume occupied by modern wind turbines and wind farms. As the WindScanner systems are a novel and extremely flexible wind measurement technology, there is an increased chance of misconducting experiments and not producing the best possible results. In order to maximize the benefits of using the WindScanner technology, there is a need to establish a methodology for WindScanner-based atmospheric experiments.

In this paper, we propose such a methodology. The methodology will be discussed through its application to a pilot experiment, Perdigão 2015, that took place in a complex and forested site in Portugal, where the two WindScanner systems were operated simultaneously for the first time. In addition, the methodology and operation of the WindScanner systems, this paper also presents a review of the two WindScanner systems, novel scanning methods, obser-
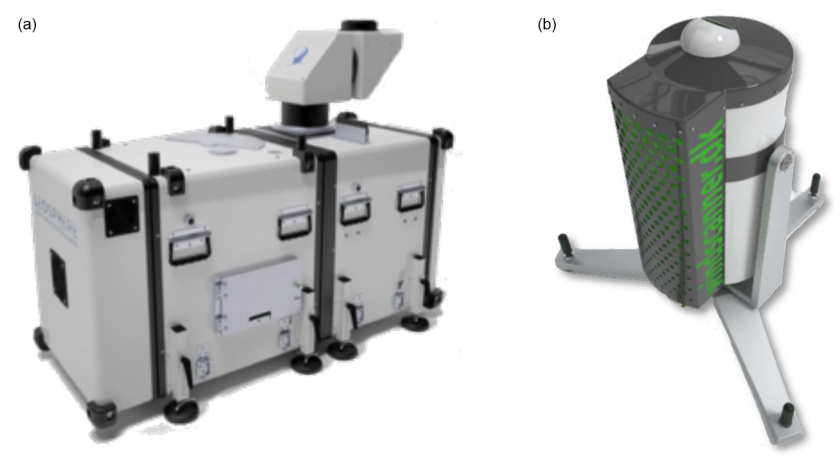

Figure 1. DTU Wind Energy scanning lidars. Long-range WindScanner (a); short-range WindScanner (b).

vational highlights of multi-lidar measurements of a single turbine wake and inflow conditions in complex terrain, multilidar measurements of wind resources along a ridge and observations of valley flows. It should be pointed out that the data analysis or discussions of particular flow situations are not the purpose of the present paper and are included as a result and as an illustration of the presented methodology.

The paper is organized as follows: Sect. 2 describes the WindScanner systems, Sects. 3 and 4 present the methodology and a detailed description of how it was applied, the results of the methodology demonstration and future work are presented in Sect. 5, while Sect. 6 provides the concluding remarks.

\section{WindScanner systems}

A WindScanner system consists of two or more spatially separated scanning lidars (long- or short-range WindScanners, Fig. 1) that are coordinated or controlled by a master computer. The first generations of the long-range WindScanner (LRWS) and short-range WindScanner (SRWS) originate from commercially available vertical profiling lidars Windcube 200 and ZephIR respectively. Under the WindScanner.dk project, DTU Wind Energy, with the expert support from specialized industrial partners, developed scanner heads, converting the profiling lidars into the scanning lidars that make up the LRWS and SRWS. In addition to the hardware developments, DTU Wind Energy developed specific software solutions for both WindScanner systems (e.g., Vasiljević et al., 2016a).

The WindScanners have been specifically tailored to perform user-defined and time-controlled scanning trajectories, known as complex trajectories, either independently or in a synchronized mode. The lidars in the long-range WindScanner system are usually connected to the master computer using a $3 \mathrm{G}$ network (Vasiljević et al., 2016b). The short-range WindScanner system is formed by connecting the master computer with the lidars via a $300 \mathrm{~m}$ long optic fiber, control- 
ling them using a MACRO (Motion and Control Ring Optical) digital interface (see Delta Tau, 2017).

SRWSs provide high-frequency measurements (up to $400 \mathrm{~Hz}$ ) of the flow while probing the atmosphere with a relatively small probe length. This allows resolving small length scales (down to a few $\mathrm{cm}$ ) and short time scales (down to $2.5 \mathrm{~ms}$ ) of the flow. As SRWSs are based on the continuous wave (CW) lidar technology there are several limitations. Since the LOS speed at a given point is resolved by focusing the laser beam, the probe length increases with range. This limits the maximum range of a SRWS to about $150 \mathrm{~m}$. Furthermore, since the beam can only be focused at a single point in time, radial velocity from one single range can be resolved. However, a high measurement rate compensates for this limitation in ranging. Based on these characteristics the short-range WindScanner system is ideal for mapping of turbulent flow features around a single wind turbine rotor (e.g., Immas et al., 2015) or around a small scale orographic feature (e.g., Lange et al., 2016).

LRWSs have a larger probe length (minimum $25 \mathrm{~m}$ ) and lower measurement frequency $(10 \mathrm{~Hz}$ at best, typically $1 \mathrm{~Hz})$ than SRWSs. Since LRWSs are based on the pulsed technology their probe length is constant with range. Furthermore, LRWSs can simultaneously retrieve radial velocity from a number of ranges along the laser light propagation path. This number is limited by the computational power of the lidar. This particular characteristic of ranging compensates for a lower measurement frequency since at any given measurement rate LRWS can provide a "snapshot" of the atmosphere up to several kilometers along a single LOS. The maximum range of LRWSs is about $8 \mathrm{~km}$, which has been typically observed in offshore conditions (Floors et al., 2016). Due to its characteristics, the long-range WindScanner system is primarily intended for measurements of mean flow fields within a large area of the atmosphere (e.g., Berg et al., 2015).

A summary of the characteristics of the two types of WindScanners is given in Table 1. A more detailed description of the long-range WindScanner system is provided in Vasiljević (2014b) and Vasiljević et al. (2016a), while Mikkelsen et al. (2011) and Sjöholm et al. (2014) include additional details on the short-range WindScanner system.

Based on the characteristics of the two multi-lidar instruments, the long- and short-range WindScanner systems are complementary to each other. Combining these two systems into a hybrid system unlocks a possibility of simultaneously observing mean flow features over a large region and turbulent characteristics and fine flow structures within a preselected area (not larger than a rotor-swept area) of this same region. At the current state of the lidar technology, we cannot have all these capabilities within one single system.

The campaign Perdigão 2015, described in the present paper, was the first attempt to simultaneously operate both long- and short-range WindScanner systems with an aim of combining them into a hybrid WindScanner system and acquiring both mean and turbulent flow features of the site.

\section{Methodology}

The methodology for WindScanner-based experiments consists of 10 steps: (1) definition of scientific objectives, (2) site selection, (3) site characterization, (4) experiment layout design, (5) scanning modes design, (6) infrastructure planning, (7) deployment and calibration, (8) execution and data collection, (9) decommissioning and post-calibration, and (10) data archiving and dissemination.

Defining scientific objectives is related to outlining scientific questions of interest that can be addressed with WindScanner observations. According to the scientific objectives, the site selection is made and followed by a detailed site characterization (e.g., wind conditions, terrain). Sometimes the order is reversed - a known site can stimulate a scientific question.

In the following steps, the experiment layout is made and physical infrastructure is planned (e.g., power, network, access roads). Afterwards, given the now-established logistical constraints, the scanning modes to be implemented during the campaigns are designed. Once the physical installation commences, the deployment and calibration procedural steps are applied (e.g., leveling and orientation of WindScanner, assessment of pointing accuracy). Following the start of the campaign, the execution and data collection procedural steps are put in action (e.g., experiment monitoring and information logging). The decommissioning and post-calibration procedural steps are applied at the end of the campaign. In the last procedural step, all the data regarding the campaign are collected together with the acquired datasets and uploaded to an online information system, making them available for end users.

The aforementioned steps will be demonstrated in the content of the Perdigão-2015 experiment in the following section.

\section{Perdigão-2015 implementation of methodology}

There were multiple reasons in favor of the Perdigão-2015 experiment: there was the need to test both the equipment and our human resources in a demanding field experiment. The question was whether the new scientific equipment, which is expensive, fragile and sensitive, and has been developed and tested previously in a laboratory environment or in shortduration field campaigns was robust enough to withstand realistic conditions; for instance, high temperatures and remote locations with no power or network grid. The equipment, transported by road between Roskilde (Denmark) and Serra do Perdigão (Portugal) and remained in the mountains without surveillance for long periods.

WindScanner.eu (2012-2015) is a European Union project of the European Strategy Forum on Research Infrastructures program, under which a 3-year preparatory phase for establishing a pan-European research infrastructure was fi- 
Table 1. Characteristics overview of the WindScanners.

\begin{tabular}{lll}
\hline & Long-range WindScanner & Short-range WindScanner \\
\hline Technology & Pulsed & Continuous wave (CW) \\
Range $(\mathrm{m})$ & 50 to 8000 & 10 to 150 \\
Maximum measurement rate $(\mathrm{Hz})$ & 10 & 400 \\
Range gates per LOS & up to 500 & 1 \\
Probe length $(\mathrm{m})$ & 25,35 or 70 (fixed with range) & 0.2 to 40 (evolving with range) \\
Scanner head & Triple-mirror based, gear-box driven & Double-prism based, belt driven \\
Atmospheric coverage & Hemisphere & $120^{\circ}$ cone \\
Weight $(\mathrm{kg})$ & 180 & 300 \\
Peak power consumption $(\mathrm{kW})$ & 1.7 & 2.4 \\
Environment protection & IP65 & IP62 \\
Temperature range $\left({ }^{\circ} \mathrm{C}\right)$ & -10 to 40 & -10 to 40 \\
\hline
\end{tabular}

nanced. Among the project deliverables, the methodology for WindScanner-based field experiments (which we report in the present paper) was developed based on the previous extensive work done under the WindScanner.dk project (see Vasiljević et al., 2016a; Sjöholm et al., 2014). The methodology was brought in to be tested and was further improved in a campaign held in Kassel (Germany) during the summer of 2014 (Pauscher et al., 2016; Vasiljević et al., 2016a).

Perdigão 2015 was a last demonstration campaign within the WindScanner.eu project that served as the preparation for the larger experiment conducted within the NEWA project (New European Wind Atlas, Mann et al., 2017) at the same site in 2017. Perdigão 2015 took place during the summer of 2015, from 4 May until 29 June.

\subsection{Step 1: definition of scientific objectives}

In addition, the WindScanner.eu project, Perdigão 2015 was funded by the NEWA, Unified Turbine Testing (UniTTe), and Wind Farm Layout Optimization in Complex Terrain (Far$\mathrm{mOpt}$ ) projects. The latter three projects have specific research goals that assisted in defining scientific objectives for Perdigão 2015.

The NEWA project aims to improve wind resource modeling for different site conditions. Areas with steep ridges and forested terrain are of particular interests since the current engineering (linear) flow models are unable to correctly predict the behavior of the flow over the sites with these features (Palma et al., 2008). The UniTTe project is focused on improving international standards for characterizing the wind power and load measurements of wind turbines on various sites (e.g., flat and complex terrain) by substituting mastbased measurements with measurements derived by nacellemounted lidars measuring close to the turbine rotor. To fulfill this project's ambition, it is necessary to investigate how the incoming flow is modified by a wind turbine. The objective of the FarmOpt project is to develop numerical tools for wind farm layout optimization in complex terrain. Here it is necessary to adequately model the wind turbine wake in com- plex terrain. To address the aforementioned scientific questions, all three projects, NEWA, UniTTe and FarmOpt, call for wind field measurements in complex terrain, preferably measurements of both mean and turbulent characteristics of the flow field, where UniTTe and FarmOpt specifically require that those measurements are done in the vicinity of a wind turbine rotor. Perdigão 2015 offered the opportunity to acquire such measurements.

For Perdigão 2015, we selected several flow aspects to investigate and addressed them with WindScanner measurements. To assist the NEWA project, we chose to measure wind resources along a ridge, occurrences of flow separations on lee sides of hills (i.e., recirculation zone) and valley flows. For the FarmOpt project, we intended to characterize a single wind turbine wake in horizontal and vertical planes. Specifically, we aimed to provide measurements for studying the wind speed deficit up to five diameters downstream of the wind turbine, the wake position in a vertical plane close to the wind turbine, and the wake geometry in a horizontal plane with center at the wind turbine hub. Similarly, for the UniTTe project, the inflow conditions were intended to be characterized in the same planes. The objective was to derive datasets for a detailed investigation of the wind turbine induction zone in complex terrain. The ultimate objective was to create a dataset that could be used in the appraisal and development of computational models for wind resource, wind turbine design and wind farm layout optimization in complex terrain.

\subsection{Step 2: site selection}

According to the scientific objectives, the site of interest should be in a terrain consisting of a hill with a steep ridge where an isolated wind turbine is operating. The site complexity should be within manageable levels, i.e., yielding a flow complexity that we can still understand. The hill size should be such that the flow clearly separates. Ideally, the hill should be in an environment surrounded by flat terrain, on which a well-defined flow would impinge, providing 
clear boundary conditions. Providing that this requirement is almost never met in nature, realistically, the surrounding terrain's complexity should be significantly lower than the selected site's complexity. A quasi two-dimensional, or a long-ridge, hill is a logical choice, and, to assure a twodimensional flow, dominant winds should be perpendicular to the ridge. Land cover, particularly forests, would add to the flow complexity and is considered desirable since many wind farms are installed near or within forested regions. According to these criteria, the Perdigão site was selected. The presence of a wind turbine at the site provided the opportunity for wake and inflow measurements.

It should be noted that the site selection is typically made considering specific criteria or the site itself triggers ideas for experiments. In the case of the Perdigão site, it was both. In 2009, the site visit initiated the idea for a double-hill experiment. In 2014, due to the presence of the wind turbine, the site became an eligible location for a measurement campaign addressing the wake and inflow conditions of wind turbines in complex terrain.

\subsection{Step 3: site characterization}

Perdigão (Fig. 2) is formed by two parallel ridges, with southeast-northwest orientation and a distance circa $1.4 \mathrm{~km}$, that measure about $4 \mathrm{~km}$ lengthwise and are $500-550 \mathrm{~m}$ above sea level (a.s.l.) at their summits. The valley-to-peak height is about 200 to $250 \mathrm{~m}$ and the hills are steep, with an inclination of approximately $35 \%$. A double ridge in comparison to a single-ridge site provides a list of additional advantages because the lee-side flow is also the flow impinging on the second ridge. Furthermore, the lee side of the first hill and the upwind side of the second hill make up the valley flow. The terrain coverage is irregular, made of no or lowheight vegetation and patches of eucalyptus and pine trees. Southwest and northeast from the ridges the terrain flattens somewhat, providing an environment that to a first approximation can provide definable inflow conditions. An Enercon E-82 $2 \mathrm{MW}$ operating wind turbine is located on the south ridge (Fig. 2).

Perdigão is an ideal site in terms of the orography and main road access, but with a difficult access to the ridges. The access to ridges is mostly through poorly maintained, steep and narrow unpaved roads, which creates difficulties for the equipment installation. During late springs and summers, the daytime temperatures are frequently above $30^{\circ} \mathrm{C}$, which imposes a challenge for field work. Overall, Perdigão provided a unique and demanding environment.

The site orography and canopy were mapped in March 2015 during a helicopter laser mapping mission. The area of $20 \mathrm{~km}^{2}$ was scanned, showing a density of about 40 points per square meter. Orthophotos with a resolution of 5 and $20 \mathrm{~cm}$ of the same area were acquired along with the derived point cloud. Wind measurements from the site were available from a $40 \mathrm{~m}$ meteorological tower (INEGI, 2005)
Table 2. Wind characteristics (January 2002-December 2004).

\begin{tabular}{lrrr}
\hline Height (a.g.l.; m) & 10 & 20 & 40 \\
\hline Measured days & 1096 & 1096 & 1096 \\
\hline Wind speed & & & \\
\hline Mean $\left(\mathrm{m} \mathrm{s}^{-1}\right)$ & 5.0 & 5.0 & 5.8 \\
Max $\left(\mathrm{m} \mathrm{s}^{-1}\right)$ & 24.8 & 23.8 & 22.8 \\
\hline Turbulence intensity & & & \\
\hline$V>5 \mathrm{~m} \mathrm{~s}^{-1}(\%)$ & 10.0 & 8.9 & 9.1 \\
$14<V<15 \mathrm{~m} \mathrm{~s}^{-1}(\%)$ & 8.5 & 7.7 & 8.6 \\
\hline Weibull parameters & & & \\
\hline$A\left(\mathrm{~m} \mathrm{~s}^{-1}\right)$ & 5.6 & 6.3 & 6.5 \\
$k$ & 1.8 & 2.0 & 2.0 \\
\hline
\end{tabular}

from January 2002 to December 2004 (3 years, Table 2), with an $88 \%$ availability at location 33997 Easting, 3529 Northing and an altitude of $489 \mathrm{~m}$ a.s.l. at three heights (10, 20 and $40 \mathrm{~m}$ ) above ground level (a.g.l.). The predominant winds were from the northeast and west-southwest directions (Fig. 3), i.e., perpendicular to the ridges, with a mean and maximum wind speed of around 6 and $20 \mathrm{~m} \mathrm{~s}^{-1}$ respectively (Table 2 and Fig. 3). These directions are also those with highest average velocity (Fig. 3) and lowest levels of turbulent intensity.

\subsection{Step 4: experiment layout design}

Computer simulations (Gomes, 2011) based on the VENTOS $^{\circledR}$ Castro et al. (2003) code of the flow over Perdigão were of importance while designing the experiment layout. VENTOS ${ }^{\circledR}$ is a dedicated CFD code for solving atmospheric boundary layer (ABL) flows over complex terrain, based on the elliptical RANS equations and the $k-\varepsilon$ model for turbulence closure. The flow domain is described with a terrain-following structured mesh, with the bottom boundary modeled as a rough surface wall, a classic inlet and outlet boundary conditions, a symmetry condition imposed at the lateral boundaries and a zero-shear condition for the top boundary. The terrain map of Perdigão was sourced from Shuttle Radar Topography Mission (SRTM) data $(90 \mathrm{~m} \times 90 \mathrm{~m}$ local horizontal resolution) combined with $10 \mathrm{~m}$ resolution height contour chart data closer to the site. Domain meshes covering a $20 \mathrm{~km} \times 20 \mathrm{~km}$ area around the site were produced and discretized using a grid of $100 \times 100$ nodes measuring a minimum of $20 \mathrm{~m} \times 20 \mathrm{~m}$ at the meteorological mast position of previous wind resource studies (Table 3). The domain ceiling was set at $3000 \mathrm{~m}$ a.s.l., discretized with 60 nodes, with the smallest at a $2 \mathrm{~m}$ height above the ground surface. No canopy areas were considered. The solution was obtained using steady state formulation for the equations, and the model's wall boundary parame- 

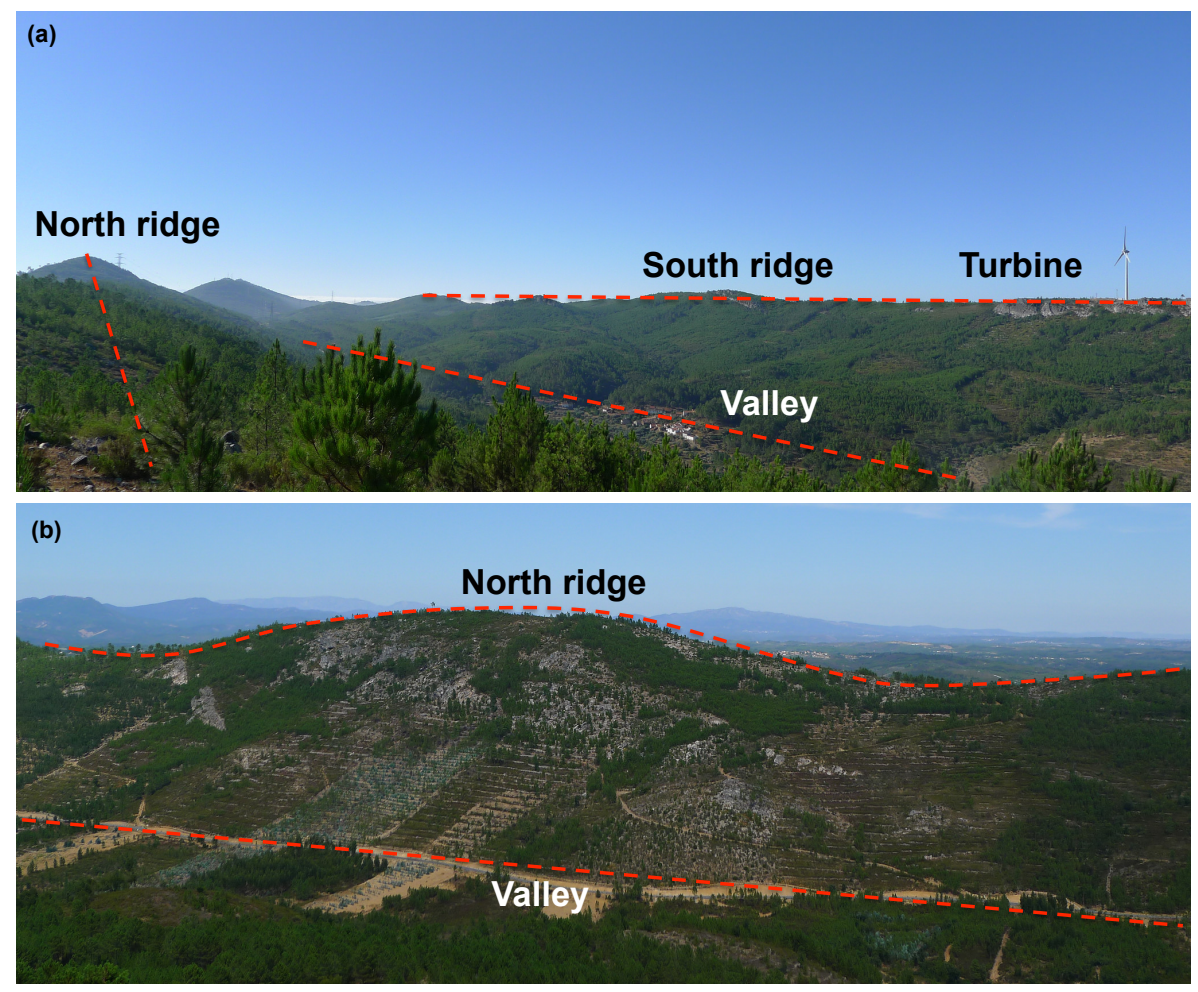

Figure 2. Perdigão site in September 2014 (see Vasiljević, 2014a). Views from the north ridge (a) and south ridge (b).
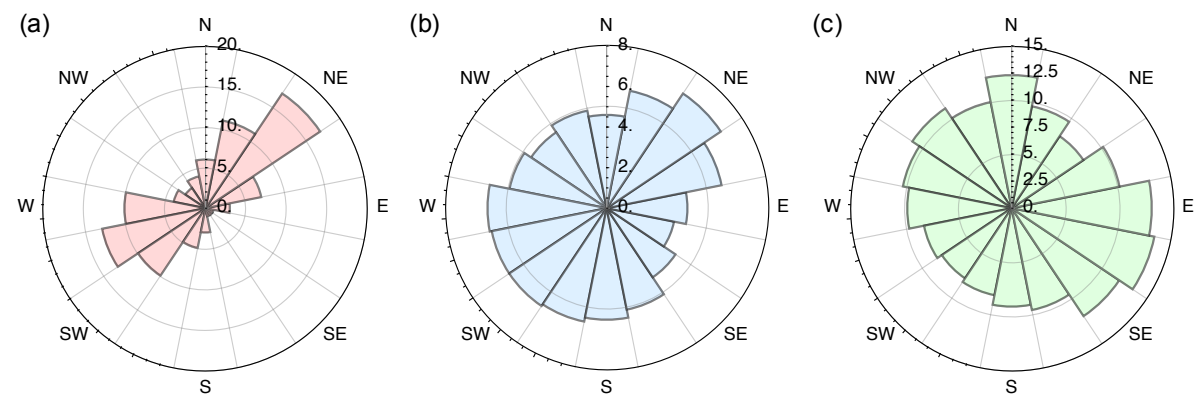

Figure 3. Wind regime at met mast station for 3-year period at $40 \mathrm{~m}$ a.g.1.: (a) wind direction (\%); (b) wind speed (m s ${ }^{-1}$ ); (c) turbulence intensity $(\%)$.

ters were calibrated to yield wind speeds of $5-6 \mathrm{~m} \mathrm{~s}^{-1}$ at the south ridge under southwest winds, with a surface characteristic roughness $z_{0}$ set to 0.03 and friction velocity $u_{*}$ set to $0.23 \mathrm{~m} \mathrm{~s}^{-1}$. The simulations of the flow from the northeast and southwest predict a high complexity of the flow (Fig. 4) and large recirculation zone enclosed in the valley (Fig. 5).

The two WindScanner systems comprised a total of six scanning lidars: three LRWSs, named Koshava (LR1), Sterenn (LR2) and Whittle (LR3); and three SRWSs, named R2D1 (SR1), R2D2 (SR2) and R2D3 (SR3). The lidar locations were selected with the aim of sampling the flow field along the south ridge and within the transect perpendicular to the ridges that goes through the wind turbine (Fig. 6 and Table 3), while taking into account intersecting angles between laser beams and elevation angles at which the laser beams will be directed.

We define the intersecting angle as the smallest angle between the projections of two intersecting laser beams in a horizontal plane. The intersecting angle can take any value between 0 and $90^{\circ}$. When selecting lidar locations we intend to have an intersecting angle of at least $30^{\circ}$ with respect to the prevailing wind direction. Based on a simple accuracy model (see Vasiljević and Courtney, 2017) the intersecting angle of $30^{\circ}$ results in an accuracy of about $0.25 \mathrm{~m} \mathrm{~s}^{-1}$ for the retrieved horizontal wind speed. In order to accurately retrieve the vertical wind speed, the elevation angles should be as steep as possible, preferably $90^{\circ}$ as indicated in Debnath et al. (2017). Hence, based on this study's results, which 

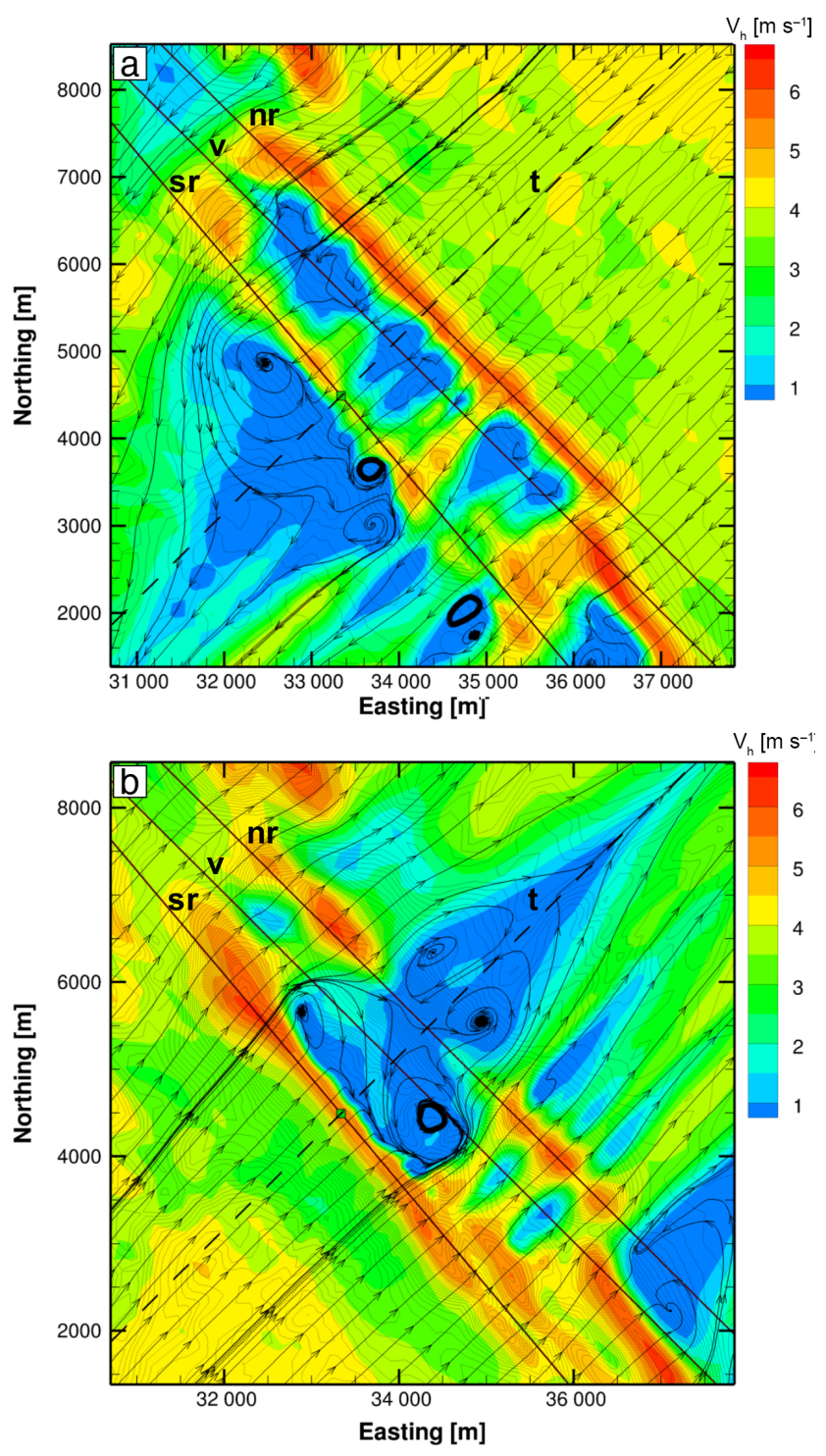

Figure 4. Simulated wind flow on a surface $80 \mathrm{~m}$ a.g.1.: (a) northeast winds; (b) southwest winds. Positions expressed in datum ETRS89/PTM06 (m) (EUREF, 2016). Three thick diagonal lines denoted as sr, $v$ and $\mathrm{nr}$ represent the south ridge, valley and north ridge lines. The dashed line denoted $t$ represents the transect of interest.

uses a norm approach described in Simley et al. (2016) to assess the suitability of the multi-Doppler setup, the elevation angles larger than $45^{\circ}$ provide means to accurately acquire the vertical component.

The previously acquired point cloud and orthophotos assisted in choosing the most accessible locations for the WindScanners' installation with respect to the previously established criteria. LR3 was located on the south ridge next to the wind turbine, and LR1 and LR2 were located on the north ridge (Fig. 6a). The distance from LR3 to LR1 and from LR3 to LR2 was about $1.5 \mathrm{~km}$, while the distance between LR1

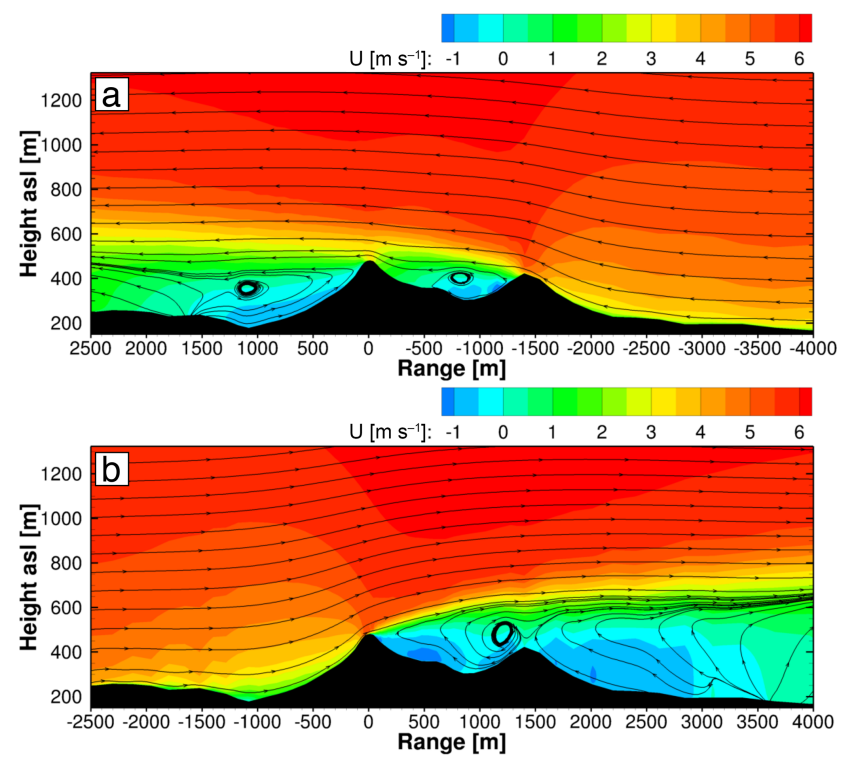

Figure 5. Simulated wind flow in a vertical plane indicated by the dashed line in Fig. 4: (a) northeast winds; (b) southwest winds. The coordinate system origin corresponds to the wind turbine base.

and LR2 was about $1.2 \mathrm{~km}$. The three SRWSs were located on the south ridge close to the wind turbine (Fig. 6b): SR1 and SR3 close to the access road, $52 \mathrm{~m}$ southeast and $45 \mathrm{~m}$ northwest of the wind turbine respectively; and SR2 $43 \mathrm{~m}$ northeast of the wind turbine, down the slope of the south ridge (Table 3 and Fig. 6b).

\subsection{Step 5: infrastructure planning}

The field campaign's control center, consisting of the LRWS and SRWS master computers, data processing computer, network appliances, WiFi antennas, security camera and a small work space, was installed in an office container, $20 \mathrm{~m}$ northeast from the wind turbine. Power and internet connections were provided from the wind turbine substation by pulling $200 \mathrm{~m}$ long power and fiber-optic cables from the substation to the control center, from which the wired power and internet connections were further distributed to the nearby WindScanners. For network redundancy, a secondary Internet connection for all devices was provided via mobile network connections. For the uninterrupted communication and power of LR1 and LR2 on the opposite (north) ridge, two unidirectional WiFi links from the control center were configured and a power container was located on the northeast slope of the north ridge approximately $1 \mathrm{~km}$ from each lidar unit (Fig. 6). The power container included two diesel generators and a fuel tank large enough for a 1-week operation without refueling. At any moment, only one diesel generator was operational, while the second one served as a fallback solution. The WindScanner locations were prepared by the local municipality to ensure a well-leveled base for the de- 
Table 3. Position of instruments and landmarks given in datum ETR89/PTM06 (m).

\begin{tabular}{lrrrrr}
\hline $\begin{array}{l}\text { Landmark/ } \\
\text { instrument }\end{array}$ & $\begin{array}{r}\text { Easting } \\
(\mathrm{m})\end{array}$ & $\begin{array}{r}\text { Northing } \\
(\mathrm{m})\end{array}$ & $\begin{array}{r}\text { Height } \\
(\mathrm{m})\end{array}$ & $\begin{array}{r}\text { Distance to } \\
\text { turbine }(\mathrm{m})\end{array}$ & $\begin{array}{r}\text { Direction to } \\
\text { turbine }\left(^{\circ}\right)\end{array}$ \\
\hline Koshava - LR1 & 34793.95 & 4806.36 & 450.15 & 1553.37 & 76.30 \\
Sterenn - LR2 & 33983.37 & 5722.43 & 443.71 & 1462.11 & 28.54 \\
Whittle - LR3 & 33298.12 & 4430.08 & 485.58 & 15.50 & 122.82 \\
R2D1 - SR1 & 33282.19 & 4491.10 & 486.19 & 52.79 & 356.77 \\
R2D2 - SR2 & 33327.27 & 4437.05 & 474.83 & 43.12 & 91.89 \\
R2D3 - SR3 & 33285.10 & 4393.12 & 487.27 & 45.43 & 180.08 \\
Wind turbine & 33285.16 & 4438.44 & 484.01 & - & - \\
Calibration pole & 33314.46 & 4433.14 & 487.01 & 29.92 & 100.253 \\
Telecom tower & 33287.29 & 4411.11 & 502.70 & 33.19 & 175.54 \\
Power tower & 34791.18 & 4820.50 & 512.30 & 1553.98 & 75.77 \\
\hline
\end{tabular}

ployment. It should be noted that without the local support achieving the aforementioned experiment layout would be almost impossible (see Vasiljević, 2015a, for more details).

\subsection{Step 6: deployment and calibration procedures}

After all scanning lidars were positioned, oriented and leveled at the designated locations (see Vasiljević, 2015b), their absolute positions were acquired using a multi-station (combination of total station and GPS) in conjunction with DGPS-RTK correction data (accuracy about $1 \mathrm{~cm}$ ). The correction data were provided by the Geographic Institute of the Portuguese Army. Additionally, the absolute position of several landmarks (e.g., wind turbine, telecom tower) were acquired and used for the WindScanner' calibration.

For assessing the pointing accuracy of LRWSs, selected landmarks were mapped with the LRWS laser beams using the CNR (carrier-to-noise) mapper (Vasiljević, 2014b, p. 157). The power line tower on the north ridge was mapped with LR3, whereas the telecom tower next to the wind turbine was mapped with LR1 and LR2. The comparison of the referenced and mapped positions indicated a pointing accuracy of $0.05^{\circ}$ in azimuth and elevation for all three LRWSs. From the CNR maps, we were able to determine the backlash level of $0.025^{\circ}$, which is consistent with results from previous deployments (see Vasiljević et al., 2016a). The sensing range accuracy was assessed using the same landmarks. The laser beams were steered to hit the landmarks, and we assessed the range gate positions (i.e., distances along LOS) at which the intensity of the backscattered light (CNR) was maximum since these positions correspond to the distances between the landmarks and LRWSs. We found sensing range offsets of 8, 10 and $3 \mathrm{~m}$ for LR1, LR2 and LR3 respectively, which were corrected for during the design of the scanning methods.

Since the DC component in the SRWS Doppler spectra is notched out, non-moving hard targets cannot be used to assess their pointing and sensing range accuracy. Instead of non-moving targets, for the SRWSs we employed a $12 \mathrm{~m}$ calibration pole with two motor-driven balls on the top made of low-density polyether (Fig. 7a). The rotating balls were scanned simultaneously from the three SRWSs by mapping three separate $2 \mathrm{~m} \times 2 \mathrm{~m}$ vertical planes, oriented perpendicular to the pointing direction of each instrument. In Fig. 7b, the result of such a scan is presented, where only the signals from the two rotating balls are highlighted. When the mapped positions of the balls were compared with the reference positions, we found a similar pointing accuracy level in the SRWSs to that of the LRWSs. The rotating balls were also used to assess the sensing range accuracy. The three laser beams were steered to meet the center of the top rotating ball, and the focus points were moved along the laser beam propagation paths. The results of this test, Fig. 8, depict the intensity of the backscattered signal of each of the SRWSs versus the distance of focusing and the theoretical distribution of the intensity based on the assumption that the intensity of a focused laser beam follows a Lorentzian distribution. It is assumed that the maximum intensity appears at the distance where the moving target is located in regards to a SRWS. It has been found that the calculated and measured distances corresponded to each other to within a few centimeters.

\subsection{Step 7: scanning modes design}

Five scanning modes, Table 4, were designed to investigate the flow details around the wind turbine and in the valley: ridge, diamond and transect scans, in the case of the LRWSs; and $T$ and vertical plane scans, in the case of the SRWSs.

The ridge scan was designed to address the flow above the south ridge (Table 4 and Fig. 6). The two LRWSs, LR1 and LR2, were configured to intersect their laser beams and to move the beam intersection along a curved line $2 \mathrm{~km}$ long, $80 \mathrm{~m}$ above the crest (i.e., the wind turbine hub height), following the terrain profile (see Vasiljević, 2016c). The line was designed using the point cloud information. The mean elevation angle at which both laser beams were directed was $4.11^{\circ}$. Throughout the scan, on average the intersecting angle between the two laser beams was $42.21^{\circ}$. 
(a)

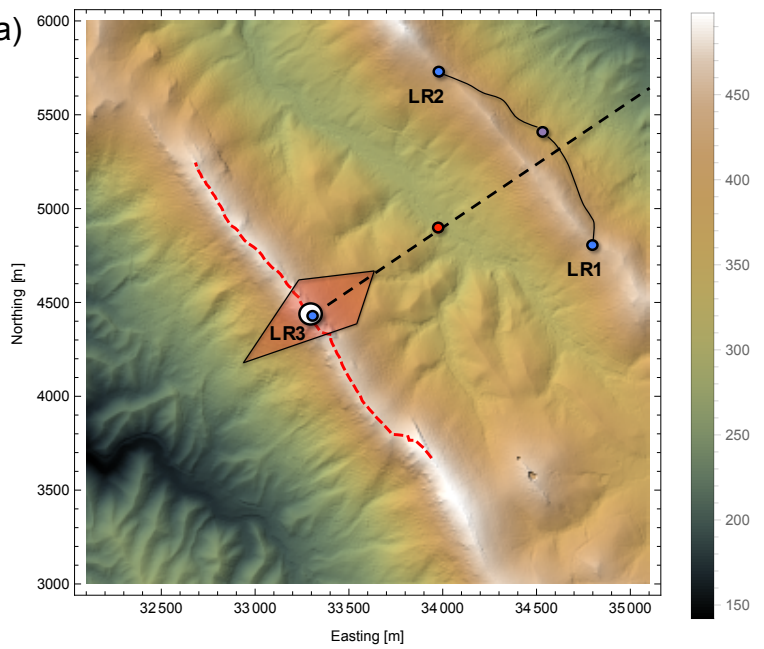

(b)

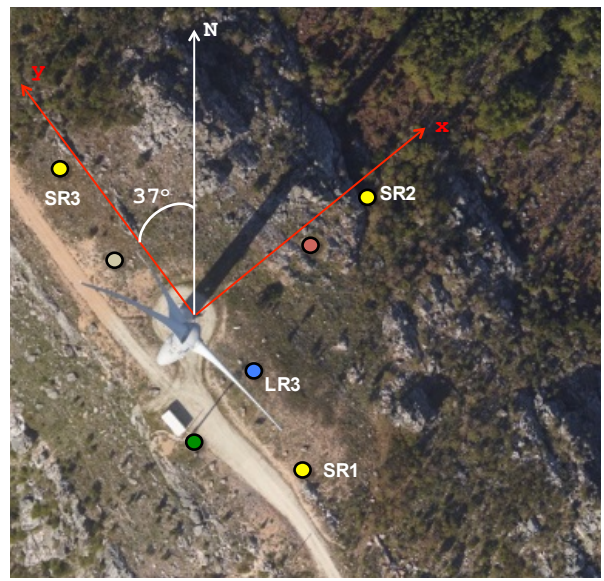

Figure 6. Perdigão site: (a) overall view (blue circles, long-range WindScanner units; white circle, wind turbine; pink quadrilateral, diamond scan; dashed black line, transect scan; red circle, virtual mast scan; solid black lines, power cables; red dashed line, ridge scan); (b) top view around the wind turbine (yellow circles, shortrange WindScanner units; blue circle, long-range WindScanner unit LR3; grey circle, control center; red circle, calibration pole; green circle, telecom tower and substation).

To investigate the inflow and wake conditions of the wind turbine at a large scale, LR1 and LR2 were configured to guide the laser beams within a $4.7^{\circ}$ vertically inclined quadrilateral with the center at the turbine hub and dimensions of $500 \mathrm{~m} \times 750 \mathrm{~m}$. The quadrilateral lies on an inclined horizontal plane defined by LR1, LR2 and hub position. The wind turbine hub represented the middle point of a $1 \mathrm{~km}$ long diagonal of the quadrilateral. Along this diagonal, LR1 and LR2 synchronously intersect laser beams and move the beam intersection resolving instantaneous horizontal wind speed and wind direction (true dual-Doppler) at 50 points - thus every $20 \mathrm{~m}$ (see Vasiljević, 2016a). Since the beams were guided within the same plane, this allowed the retrieval of horizontal wind speed and wind direction (unsynchronized) in an additional 2450 measurement points (Table 4 and Fig. 6). In
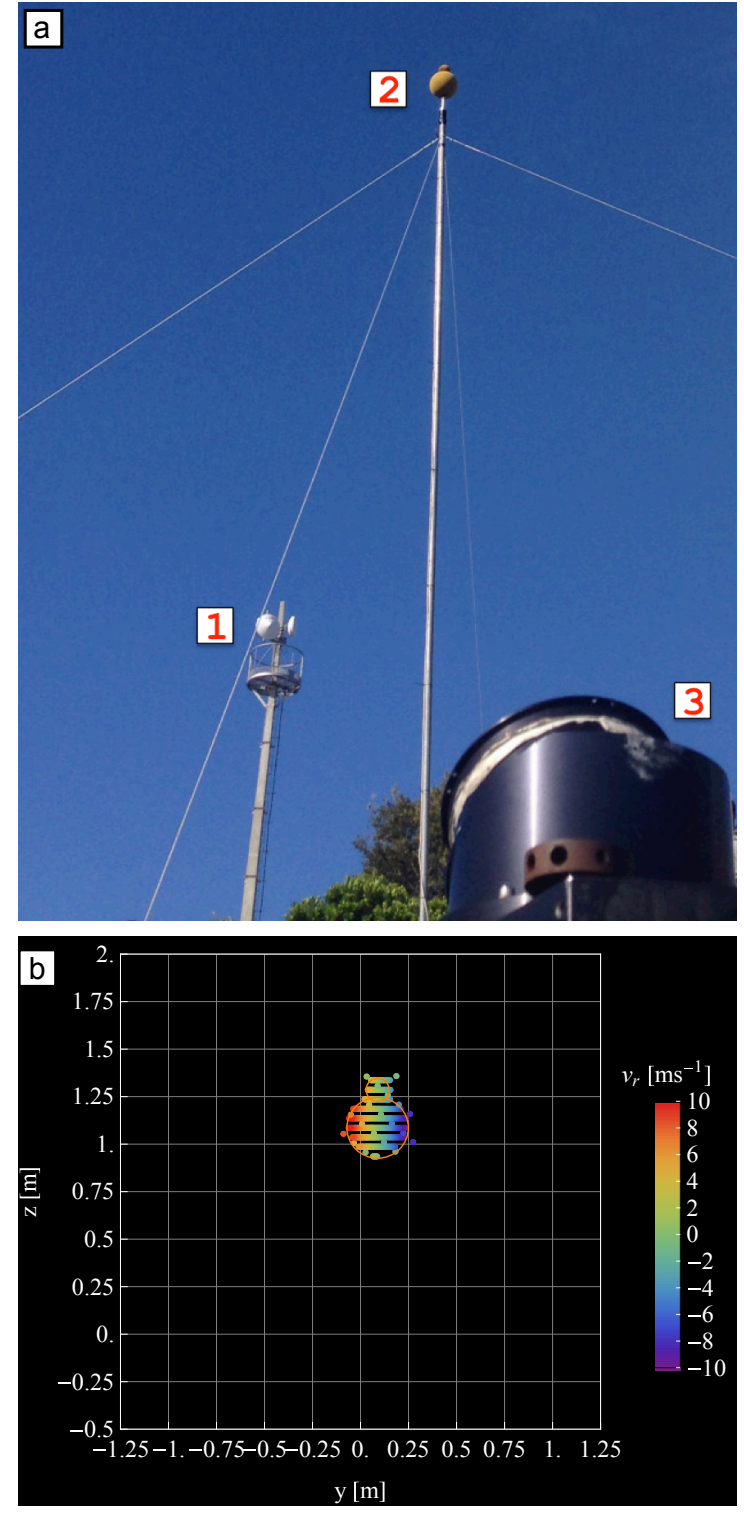

Figure 7. Calibration of the SRWS: (a) actual setup (1 - telecom tower, 2 - calibration pole with two motor-driven balls and 3 SRWS's scanner head); (b) radial wind speeds induced from the rotation of the two rotating balls as measured by SR1 (the perimeter of the two balls is depicted with orange circles).

these additional points, LR1 and LR2 acquire radial wind speed asynchronously. The scan mode was named the diamond scan. It is important to notice that the diamond scan does not consist of two synchronized plan position indicator (PPI) scans, but of two synchronized user-defined scans. Moving a laser beam within an inclined horizontal plane requires a variable elevation angle which is a function of the azimuth angle. Since the wind characteristics are such that the wind direction is mainly either northeast or southwest, the diamond scan can be used to measure the inflow and wake simultaneously. The objective with the diamond scan was to 


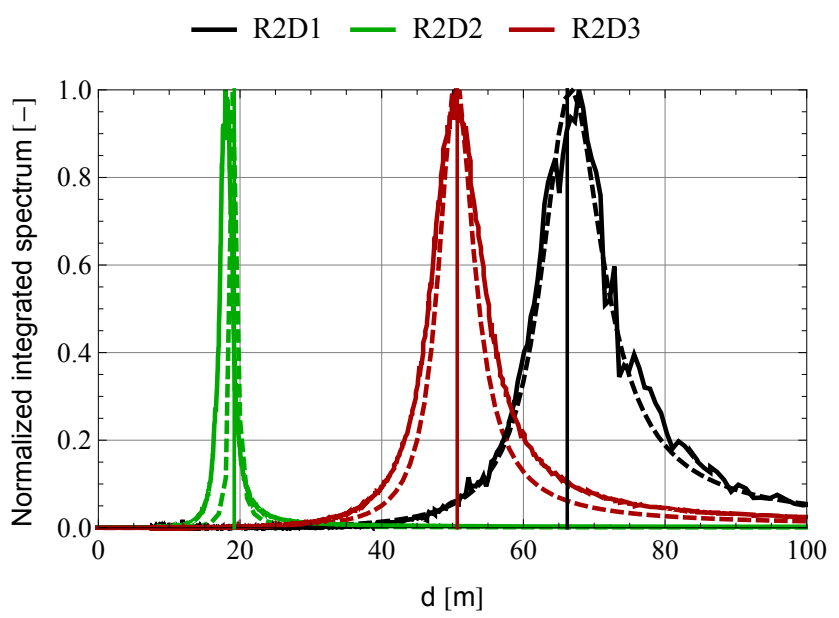

Figure 8. Integrated spectrum versus focus distances for SR1 (R2D1, black line), SR2 (R2D2, green line) and SR3 (R2D3, red line).

obtain data for studying the wind speed deficit up to five diameters downstream of the wind turbine, the wake position, and wake geometry in a horizontal plane with the center at the wind turbine hub, as well as the inflow conditions up to five diameters upstream of the wind turbine. The average intersecting angle between the two laser beams during the diamond scan was $49.37^{\circ}$, while the average elevation angle at which the beams were directed was $4.33^{\circ}$.

In addition to the large-scale flow observations, two scanning modes for the short-range WindScanner system (Table 4 and Fig. 9) were configured to provide insights on the inflow and wake at the turbine scale. The T-scan was used to measure the turbine inflow conditions. Two different versions of this mode were used, differing in the dimensions of the scanning area. Both of them consisted of one vertical and one horizontal plane, which were perpendicular to each other and perpendicular to the south ridge line. In Fig. 9a, we can see the first version in the Cartesian coordinate system, with the origin in the wind turbine base rotated $37^{\circ}$ clockwise from north. The area covered with the first scan mode version was from -56 to $56 \mathrm{~m}$ along the $y$ axis, from 0 to $80 \mathrm{~m}$ along the $x$ axis and from 14 to $78 \mathrm{~m}$ along the $z$ axis. Within the enclosed area, 15 horizontal and 9 vertical line scans were performed. The second version covered an area from -64 to $64 \mathrm{~m}$ along the $y$ axis, from $-10 \mathrm{~m}$ to $100 \mathrm{~m}$ along the $x$ axis and from 14 to $78 \mathrm{~m}$ along the $z$ axis, encompassing 17 horizontal and 9 vertical line scans. On average, the intersecting angles between the SR1 and SR2, SR1 and SR3, and SR2 and SR3 laser beams were 44.26, 55.78 and $49.64^{\circ}$ respectively. The average elevation angle at which the beams were directed was $50.92^{\circ}$.

To address the wake conditions with the short-range WindScanner system, the vertical scan mode consisting of vertical lines was employed (Fig. 9b). Also, two different versions of the scanning mode were used. Both of them focused on scan- ning in vertical lines placed in a plane parallel to the wind turbine's rotor. The scanning plane was confined in the $y-z$ plane, between -48 and $48 \mathrm{~m}$ along $y$, and between 30 and $128 \mathrm{~m}$ along $z$. In the first version of the scanning pattern, the vertically scanned lines were located in a vertical plane one rotor diameter $(80 \mathrm{~m})$ away. In the second version, one more plane with the same dimensions was added half a rotor diameter away in the downwind direction. On average, the intersecting angles between the SR1 and SR2, SR1 and SR3, and SR2 and SR3 laser beams were 28.77, 59.96 and $49.21^{\circ}$ respectively. The average elevation angle at which the beams were directed was $49.91^{\circ}$.

While executing the second version of the $T$ and vertical scan modes, we observed a lag (loss of synchronization) between SR3 and the other two SRWSs (SR2 and SR1), which operated in sync. The lag linearly increased over the time with a constant rate of 16.67 and $5000 \mu \mathrm{s} \mathrm{s}^{-1}$ for the $T$ and vertical scan modes respectively. The observed lag was caused by the safety limits of the scanner head controller, which did not allow higher scanning speeds than the maximum permitted speed for a safe operation. As a result, SR3 was lagging behind SR2 and SR1. The reset of the scanning modes zeroed the lag, which then once again increased over time as described. The reset took place each time when we switched from one scanning mode to another. However, this was not done in a systematic way since the scanning mode switching took place when the wind direction changed from the northeast to southwest. Therefore, the values of the maximum lag for the short-range WindScanner system in Table 4 are only given for the first version of the $T$ and vertical scan modes since during their execution the SRWSs were in sync.

The transect scan was employed to investigate the flow field within a vertical plane perpendicular to the ridges entailing the wind turbine (Table 4, Figures 6 and 10). The three LRWSs were configured to perform intersecting and synchronized range-height indicator (RHI) scans. The RHI scan of LR3 coincided with the vertical plane (Figure 10), whereas other two RHI scans sliced through this plane along a $500 \mathrm{~m}$ vertical line position in the valley (see the vertical dashed line in Fig. 10). The radial wind field measured by LR3 provided the possibility to assess the recirculation zone on lee sides of either ridge in the case of southwest and northeast winds, traces of the wind turbine wake and the flow in the valley (see Vasiljević, 2016d). The intersection of the three RHI scans represented a $500 \mathrm{~m}$ virtual mast. The intersecting angle during the scan between the LR1 and LR2 laser beams was $84.10^{\circ}$, while this angle between the LR2 and LR3 laser beams and between the LR1 and LR3 was equal to 54.77 and $41.12^{\circ}$ respectively. The elevation angle at which the beams were directed was in a range from about -12 to $23^{\circ}$. Even though we had three independent LOS measurement along the virtual mast due to low elevation angles only the horizontal components of the wind vector (i.e., $u$ and $v$ ) were considered in the data analysis (see explanations in Berg et al., 2015; Debnath et al., 2017). 

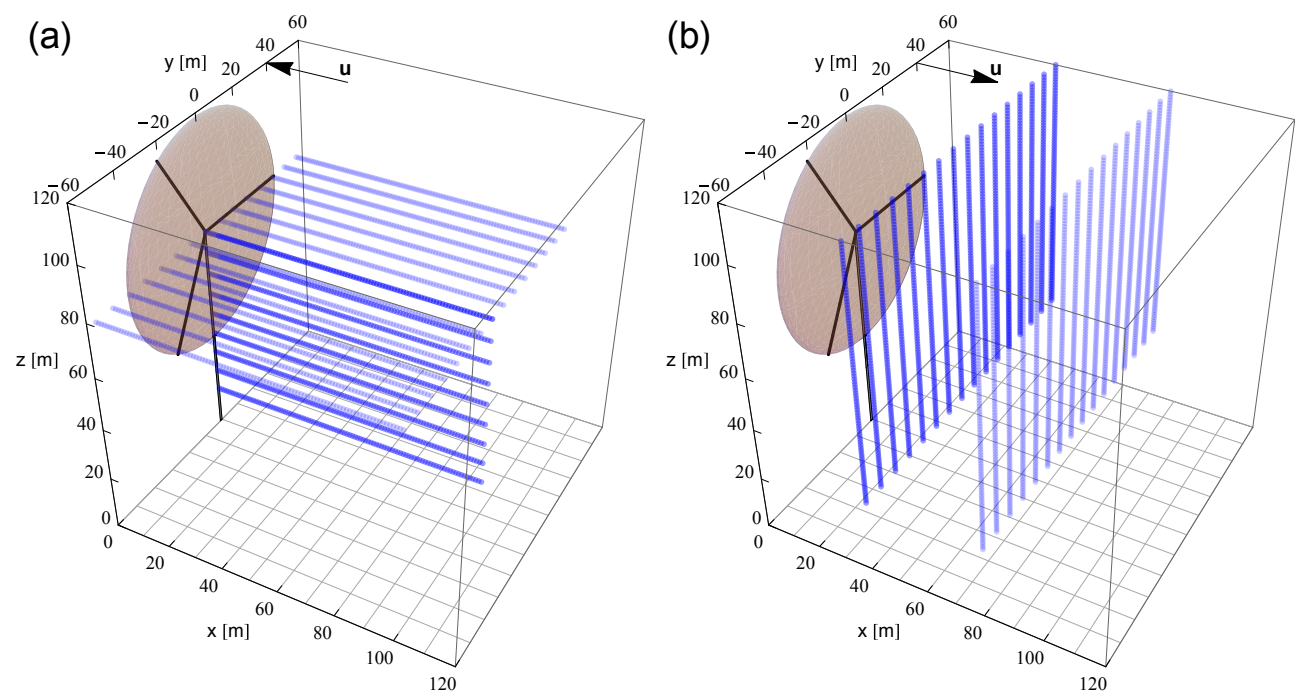

Figure 9. Scanning patterns of short-range WindScanners: (a) T-scan; (b) vertical planes.

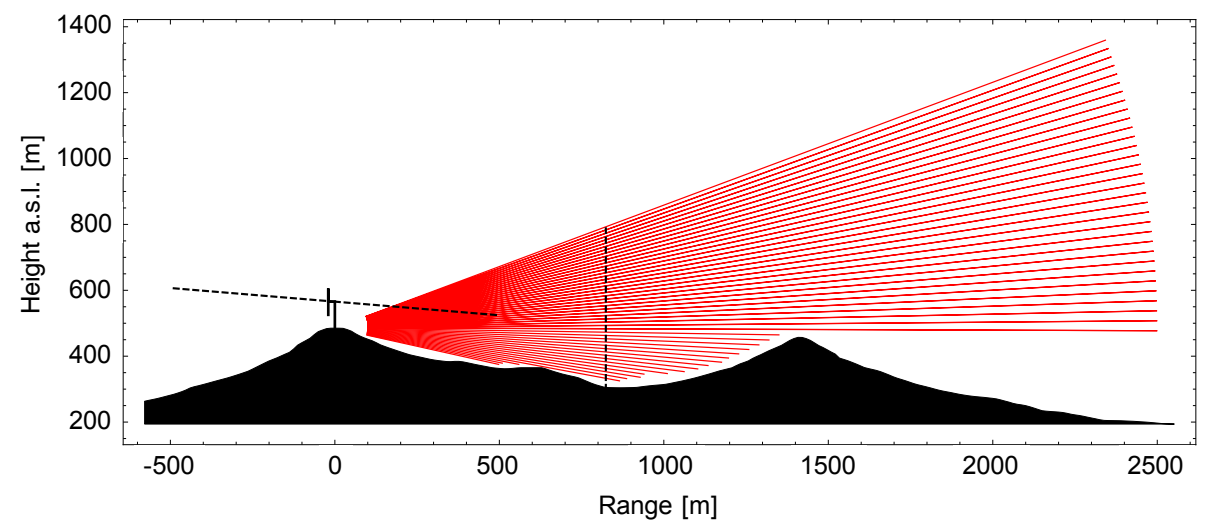

Figure 10. Transect scan: red lines indicate LOS measurements acquired by LR3, the vertical dashed line shows the position of the virtual mast, and the inclined horizontal dashed line indicates the position of the diamond scan plane.

The long-range WindScanner system's scans were run in a batch mode, where each strategy was executed over a $10 \mathrm{~min}$ period. The sequence of the ridge, diamond and transect scan was executed over a $30 \mathrm{~min}$ period and then repeated. Because only LR1 and LR2 were needed to execute the ridge and diamond scans, LR3 continued to perform the transect strategy throughout the entire campaign.

The Portuguese Institute for Sea and Atmosphere (IPMA) provided a daily forecast for the Perdigão site using a nonhydrostatic numerical weather prediction model of a limited area (AROME, the numerical prediction model of MeteoFrance) for variables such as temperature, relative humidity, rain, wind direction and velocity at $10 \mathrm{~m}$ and $80 \mathrm{~m}$ a.g.l. The wind direction was used to decide the scanning mode of the short-range WindScanner system: the vertical mode if the wind was coming from the southwest direction (wake scanning) or the T-scan mode in the case of northeast wind (inflow scanning).

\subsection{Step 8: execution and data collection}

For the experiment, visits to the WindScanners and hardware checks were performed several times per day in the first 3 weeks of the experiment, as fine adjustments of the scanning modes were needed, and then every other day in the last stage of the experiment. Also, the number of staff at the site during the first 3 weeks decreased from 10 to 1 single person, who managed the whole setup until the end. The status of the experiment was reported daily on the dedicated web blog (see Vasiljević, 2015a, for more details). The data were collected every 3rd day and transmitted to the database at DTU. Preliminary data analysis was done on the fly for quality and quantity assessing. This assessment was of particular importance since it helped in making a decision to extend the length of the experiment from the originally planned 4 weeks to the total of 8 weeks. 
Table 4. Scanning modes.

\begin{tabular}{|c|c|c|c|c|c|}
\hline \multirow[b]{2}{*}{ Scanning mode } & \multicolumn{3}{|c|}{ LRWS system } & \multicolumn{2}{|c|}{ SRWS system } \\
\hline & Ridge & Diamond & Transect & $T$ & Vertical \\
\hline \multirow[t]{3}{*}{ WindScanners } & LR1 & LR1 & LR1 & SR1 & SR1 \\
\hline & LR2 & LR2 & LR2 & SR2 & SR2 \\
\hline & & & LR3 & SR3 & SR3 \\
\hline Variables & $u, v$ & $u, v$ & $u, v, v_{\mathrm{LOS}}$ & $u, v, w$ & $u, v, w$ \\
\hline LOS sampling $(\mathrm{Hz})$ & 2 & 2 & 2 & 100 & 100 \\
\hline Points per scan & 100 & 2500 & $50 u, v, 12000 v_{\mathrm{LOS}}$ & 350 & 312 \\
\hline Scans per $10 \mathrm{~min}$ & 12 & 24 & 24 & 9 & 9 \\
\hline Probe length $(\mathrm{m})$ & 35 & 35 & 35 & $0.7-38$ & $1.7-47$ \\
\hline Synchronization (Max lag (ms)) & 10 & 10 & 10 & 20 & 20 \\
\hline Dynamic ranging & Yes & Yes & Yes & - & - \\
\hline Dynamic focusing & - & - & - & Yes & Yes \\
\hline
\end{tabular}

However, this was the first time the long- and short-range WindScanner systems were used simultaneously, and only a few periods of simultaneous measurements were collected, because of the following reasons. Despite the rapid installation of the WindScanner systems, the off-grid power solution for the long-range WindScanner system was deployed roughly 10 days after the short-range WindScanner system started collecting data. An issue with the control unit of one of the LRWSs forced us to reject the measurements during 23-25 May (see the blog post for these dates). The cooling systems of long- and short-range WindScanners could not cope with the high temperature around midday $\left(\geq 40^{\circ} \mathrm{C}\right)$ and we had to pause the measurements for a couple of hours every day. We discussed this issue more in Vasiljević et al. (2016a), where we suggested possible solutions. The shortrange WindScanner system had a technical issue with the MACRO ring which halted the observations during June.

\subsection{Step 9: decommissioning and post-calibration procedures}

At the end of the measurement period the pointing and sensing range accuracy were reassessed with the LRWSs only. We found that the new positions of the landmarks matched the previously mapped position within $0.05^{\circ}$ in azimuth and elevation for all three LRWSs. The backlash levels remained the same $-0.025^{\circ}$. The new set of sensed distances showed no difference compared to the previously acquired set. Due to technical issues of the SRWSs, the post-calibration procedure was not performed for this system. After the postcalibration procedure the WindScanners were uninstalled, and all traces of their presence removed from the sites.

\subsection{Step 10: data dissemination and availability}

The short-range WindScanner system was operational from 8 May until 3 June. During this period, 110 h (665 runs with a duration of $10 \mathrm{~min}$ each) of data were acquired. A total of 407 runs were made with the T-scan mode, addressing in- flow conditions, whereas the remaining 258 were made by employing the vertical planes mode, addressing wake conditions. The long-range WindScanner system was operational from 19 May until 26 June. Overall, the long-range WindScanner system acquired $528 \mathrm{~h}$ of data, from which about $180 \mathrm{~h}$ of data were recorded with each scanning strategy. A special case is the transect scan, where in addition to the $180 \mathrm{~h}$ of concurring data acquired with all three LRWS there is also the additional $360 \mathrm{~h}$ of data collected only by LR3. There are $6 \mathrm{~h}$ of simultaneous measurements of the inflow conditions with both WindScanner systems.

Also, for the entire measurement period (May-June) the owner of the wind turbine (Generg) provided 10 min means of the wind turbine SCADA (supervisory control and data acquisition) data.

The acquired datasets of radial velocities were entirely processed and data artifacts removed. The LRWS dataset was filtered on the CNR values of each individual measurement point (CNR $>-27 \mathrm{~dB})$. In addition to the filtering, a multirange gate analysis was applied to remove remaining spurious data points where, using multi-peak detection in the CNR values for each LOS, data points contaminated with hard targets were removed. Also, by detecting discrete jumps in the radial speed values along each LOS, errors in the spectral estimation were rejected from the datasets. Details about the multi-range gate analysis will be presented in a separate publication.

The SRWS data were first filtered to remove signals that originated from hard target motions (i.e., wind turbine blades). These signals are relatively easy to detect due to the corresponding high-intensity power spectral density that appears in the Doppler spectra, as a result of the increased backscattered light from hard targets, relative to the one from aerosols. Afterwards, the data are filtered by using an adaptive threshold of the acceptable maximum and minimum of the total energy of the laser Doppler spectra. The threshold value is calculated by the lower and upper outer fences of the distribution of the total energy per spectrum. Consequently, 
Table 5. Data availability expressed in hours.

\begin{tabular}{lrrr}
\hline & \multicolumn{3}{c}{ LRWS system } \\
\cline { 2 - 4 } Scanning mode & Ridge & Diamond & Transect \\
Data before filtering on sampling & 187 & 185 & 181 \\
Data after filtering on sampling & 77 & 94 & 116 \\
Northeasterly winds & 7.5 & 10 & 15 \\
Southwesterly winds & 19 & 16 & 12 \\
\hline
\end{tabular}

the data were spatially averaged after being grouped in cubic grid cells both of $4 \times 4 \times 4 \mathrm{~m}$ and $8 \times 8 \times 8 \mathrm{~m}$ dimensions. To treat the synchronization issues that appeared in the second versions of the T-scan and vertical plan patterns, the data acquired using those pattern versions were additionally time averaged in 10 min periods.

Where possible, the processed radial velocities were combined to calculate two (diamond, ridge and transect scanning methods) or all three components of the wind vector ( $T$ and vertical scanning method). Details about the retrieval techniques are given in Appendix A. Afterwards, the wind vector and radial fields were averaged over a $10 \mathrm{~min}$ period and plotted. The resulting figures were saved as PNG files, which were available for users to visually browse the dataset. To indicate the amount of high-quality data collected with the long-range WindScanner system, we applied a simple filter on sampling constraints after processing all data, which consisted of selecting only those $10 \mathrm{~min}$ runs where there was at least $50 \%$ of the maximum number of scan iterations and at least $50 \%$ of the maximum number of measurement points. The results are given in Table 5 only for the longrange WindScanner system. Currently, for the SRWS, each 10 min period is being manually evaluated in order to determine whether the wake or induction zone are captured with measurements. This is the reason why Table 5 does not include information on the SRWS data.

Both raw and highly processed datasets have been uploaded to a MySQL database and are currently available for the participants of the projects that funded the experiment. We intend to release the entire dataset for public use during the second half of 2017 through the e-WindLidar web platform (http://e-windlidar.windenergy.dtu.dk). At present, the data are being analyzed by the research groups directly involved in Perdigão 2015 and have been presented in appropriate forums. Examples of those presentations and publications are, for instance, found in Mann et al. (2016) for the details of the experiment; in Rodrigues et al. (2016), who focused on the flow in the valley and over the two ridges; in Hansen et al. (2016), who focused on the wind turbine wake; and in Meyer Forsting et al. (2016), who focused on the inflow conditions.

\section{Discussion}

\subsection{Observational results}

Figures 11 to 15 intend to illustrate the performance of the scanning modes and also be a sample of the flow phenomena observed during the course of the field campaign.

The ridge scan, $2 \mathrm{~km}$ along the south ridge, shows no turning of the wind for the northeast winds (Fig. 11a). Thus, for this wind direction we observed a two-dimensional flow. On the other hand, for southwest winds there is a slight turning of the wind (the difference between the wind direction at the edges of the transect is roughly $15^{\circ}$, Fig. 11b). The maximum wind speed along the transect is not seen at the wind turbine location regardless of the dominant wind direction (Fig. 11).

The initial data analysis of the wake measurements indicates a clear diurnal dependence of the wake characteristics (see Hansen et al., 2016), which may be related to the stratification. Due to the lack of temperature and heat flux measurements, we established an empirical relation between the period of a day and atmospheric stability. A well-formed, narrow and long wake was pulled down the slope during late nights until early mornings when we expected stable conditions and reduced mixing (Figs. 12a and 13a). On the other hand, during the rest of the day under more unstable conditions and increased mixing, the wake was wider, shorter and lifted up (Figs. 12b and 13b). The inflow and wake of the turbine during 1 full day is well represented in Vasiljević (2016b).

The objective of the transect scans (Fig. 14) was the mapping of the flow over the ridges and in the valley. For the dominant wind directions of the northeast and southwest (Fig. 14a and b), the recirculation zones on the lee sides (south side of the north ridge and north side of the south ridge) of the hills can be seen, as suggested by the computational results in Fig. 5. Although they share a common feature, these two figures correspond to 2 different days ( 7 and 10 of June) and two different times (03:29 and 13:43 UTC) night and day at a time of low and high temperature. The velocity field at 03:29 UTC, Fig. 14a, displays a pattern, a twolayer atmosphere of maximum wind speed at around 500 and $750 \mathrm{~m}$, and a constant wind speed between 500 and $650 \mathrm{~m}$. Figure $14 \mathrm{c}$, at around the same time in the night, displays a stratified atmosphere with a well-defined internal wave, originating in the south ridge, of a length equal to the distance between ridges (see $24 \mathrm{~h}$ animation, Vasiljević, 2016e). This phenomenon and the conditions under which it can persist, which is a subject in Rodrigues et al. (2016), will be studied further.

Figure 15 illustrates hybrid WindScanner measurements of the wind turbine inflow conditions. We can see combined measurement planes acquired by the long-range WindScanner system using the diamond scan (horizontal plane) and the short-range WindScanner system using the vertical plane scan (vertical plane). During the depicted observational pe- 

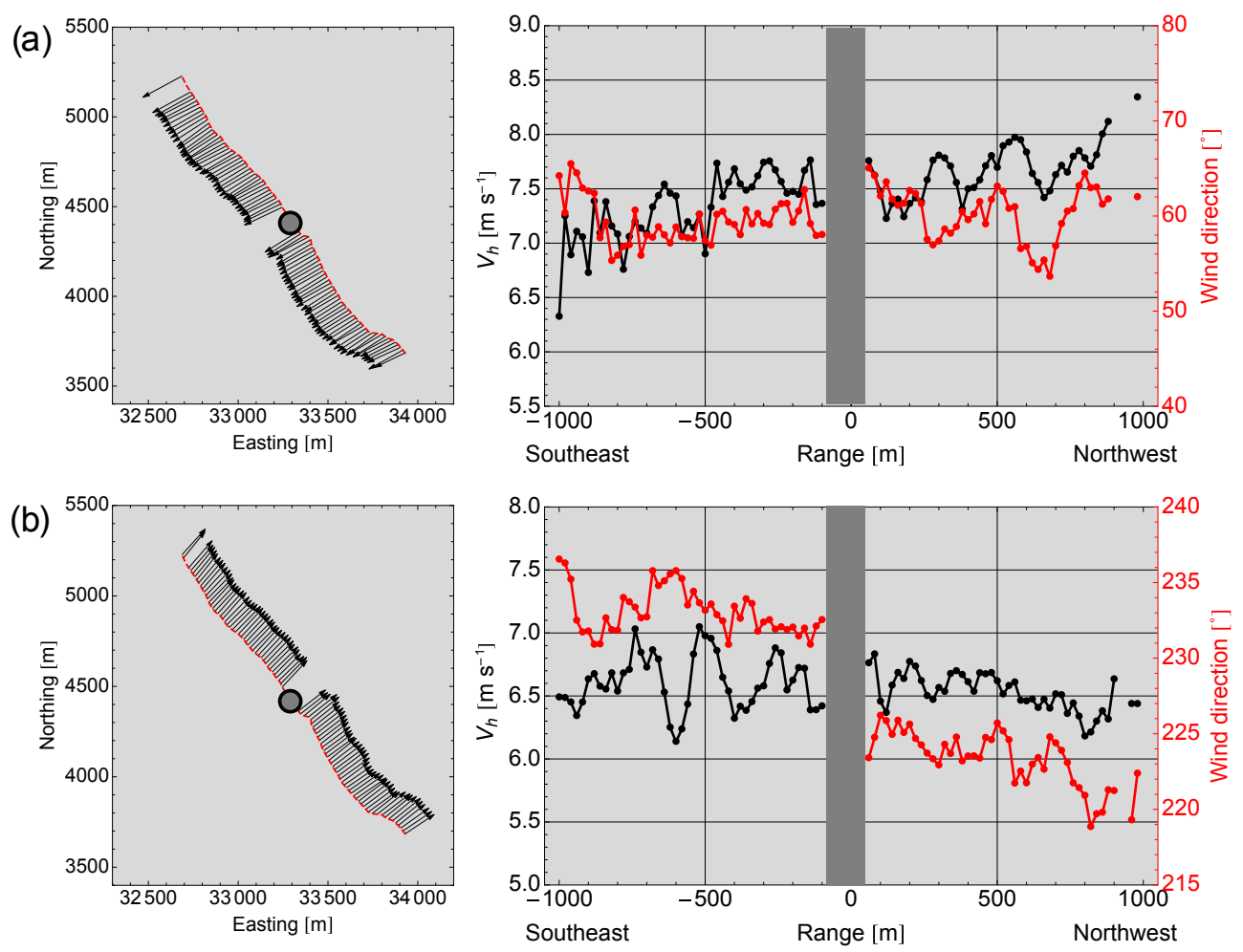

Figure 11. Wind vectors, wind speed and direction (10 min averaged) $80 \mathrm{~m}$ a.g.l. along the south ridge for wind dominant directions acquired using the ridge scan performed by the long-range WindScanner system: (a) northeast (measurements taken on 7 June 2015 from 03:30 to 03:40 UTC); (b) southwest (measurements taken on 21 June 2015 from 21:42 to 21:52 UTC). Black line, horizontal wind speed; red line, wind direction; dashed red line, ridge scan; grey circle (left) and rectangle (right) are areas where measurements are erroneous due to the presence of the wind turbine.

riod the wind direction was approximately $45^{\circ}$; thus, the rotor plane was not completely aligned with the vertical plane scan $\left(53^{\circ}\right)$, while the mean horizontal wind speed was about $4.5 \mathrm{~m} \mathrm{~s}^{-1}$ at the hub height. The comparison of the longand short-range WindScanner system horizontal wind speed measurements at horizontal lines closest to the two scanned plane intersections shows a generally good agreement (the averaged mean difference is about $0.2 \mathrm{~m} \mathrm{~s}^{-1}$ ). We should not expect the exact match between these measurements since the way in which the flow was probed at the coinciding points with two WindScanner systems differs. Throughout the diamond scan the laser beams of the long-range WindScanner system were steered within a horizontal plane, whereas the laser beams of the shot-range WindScanner system during the vertical plane scan were directed with steep elevation angles (the averaged elevation angle was about $50^{\circ}$ ). In addition, the difference in the positioning of the probes with respect to the measurement points, the probe lengths of the two WindScanner systems are also different (see Table 4). What effects the dimension and position of the intersecting probes have on the retrieved wind speed information will be studied in future publications.

\subsection{Improving the methodology}

In this paper, we presented the methodology for conducting field studies with multi-Doppler lidars. This was a preliminary attempt at outlining and defining systematic steps that can lead to the acquisition of high-quality datasets from field studies. Despite being developed for multi-Doppler lidar experiments, the methodology can be used for any field campaign. The majority of the presented steps are relevant for all field experiments (e.g., defining scientific question, planning infrastructure), while some are WindScanner specific (e.g., scanning mode design). In this paper, we presented a sequential execution of the steps. However, some steps can and should run in parallel (e.g., data archiving and dissemination with execution and data collection) and some steps can be merged together (e.g., experiment layout design and infrastructure planning).

The application of the methodology in the Perdigão-2015 experiment helped in devising future improvements. Simulation results could be used to assess whether WindScanners can capture the desired flow features by basically simulating the flow study itself. This calls for the integration of an end-to-end WindScanner measurement process simulator with a flow model (e.g., Vasiljević et al., 2011). The simula- 

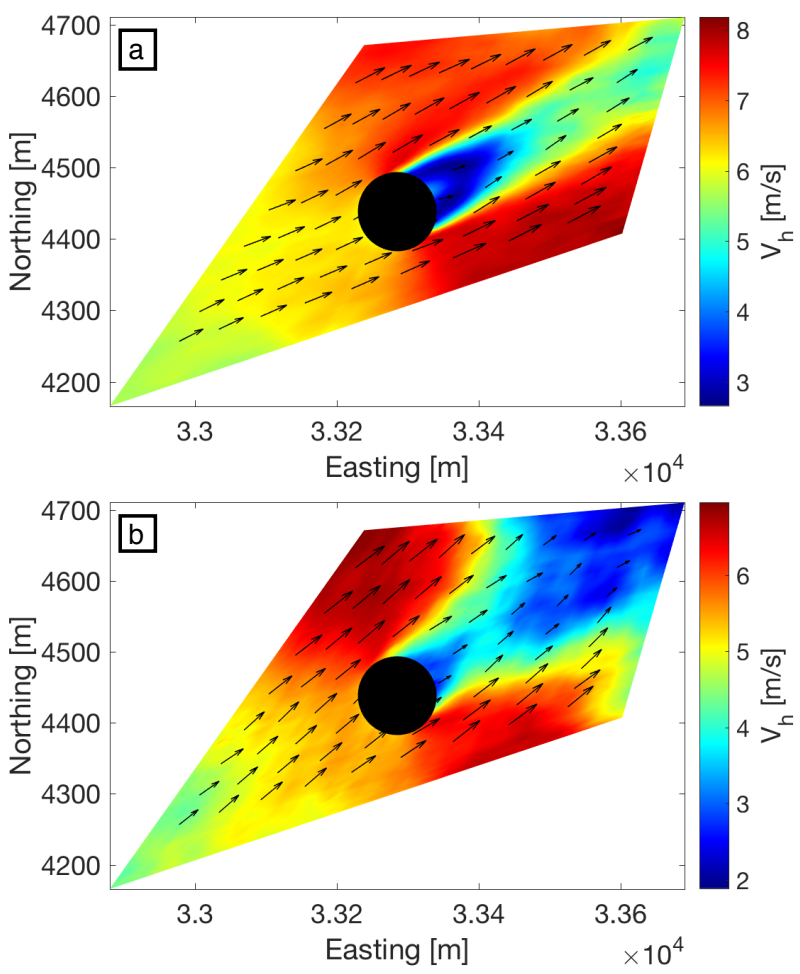

Figure 12. The wake in a horizontal plane observed with the diamond scan (10 min averaged) performed by the long-range WindScanner system for different atmospheric conditions: (a) stable conditions (measurements taken on 10 June 2015 from 22:20 to 22:30 UTC); (b) unstable conditions (measurements taken on 11 June 2015 from 16:02 to 16:12 UTC). The black circle represents the rotor-swept area.

tion of flow study is useful for selecting an appropriate type of WindScanner (pulsed and/or CW lidar) and a number of WindScanner units and for designing and optimizing scanning strategies that can capture desired flow features. The use of computer modeling prior to the field campaigns is a must, and it is a practice that will become more and more common.

As the WindScanner wind vector retrieval accuracy is influenced by the LOS uncertainty, pointing accuracy and retrieval technique, extending the simulator with the lidar measurements uncertainty model would provide grounds for a preliminary accuracy assessment and an optimization of the WindScanner installation locations (see accuracy maps in Vasiljević and Courtney, 2017). In order to track the LOS accuracy, the WindScanner measurements should be regularly checked during the field study. This can be done by employing a simple and not necessarily a tall mast on the field study site and installing at a minimum one sonic anemometer on the mast top. The mast top should be visible from every WindScanner location, and, preferably, the mast top location should coincide with one of the measurement points.

To better assess pointing accuracy, more than one hard target should be used and mapped prior, during and after the
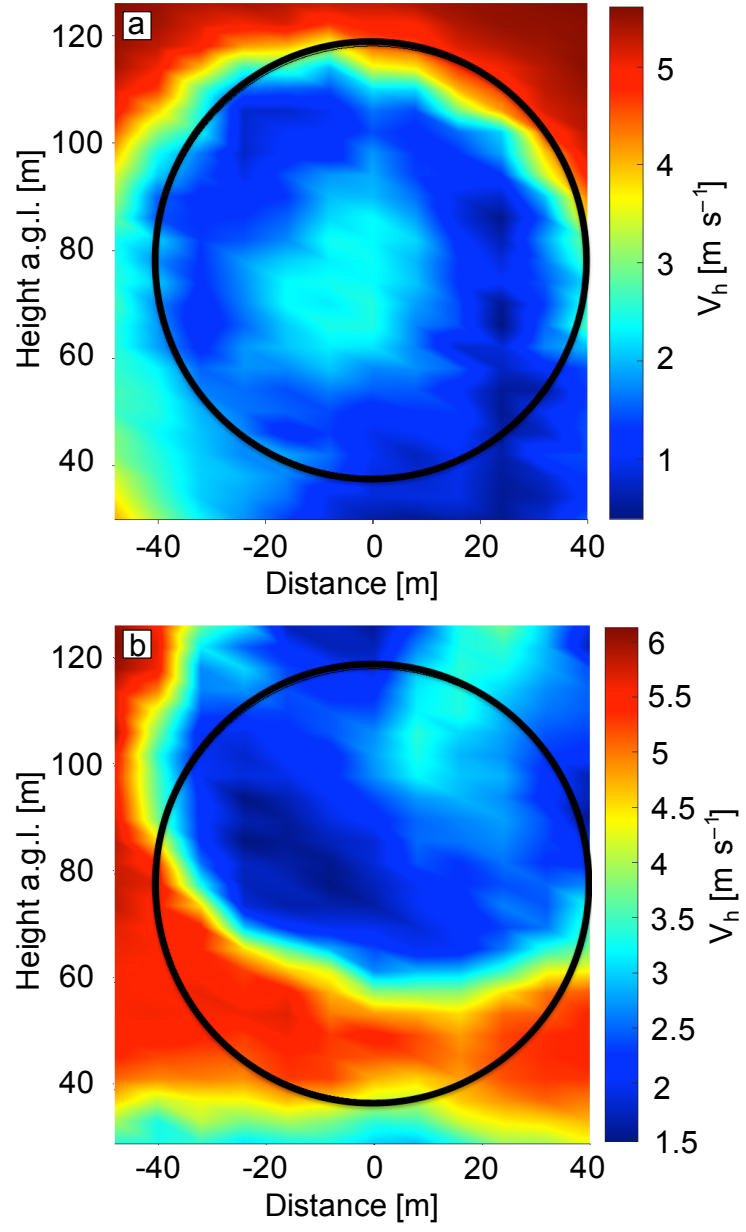

Figure 13. The wind speed (10 min averaged) wake in a vertical plane one rotor diameter away from the turbine observed with the vertical plane scans performed by the short-range WindScanner system: (a) wake pulled down (measurements taken on 12 May 2015 from 00:40 to 00:50 UTC); (b) wake lifted up (measurements taken on 12 May 2015 from 19:10 to 19:20 UTC). Black circle, rotorswept area.

field study. The number of hard targets could correspond to the number of error sources (e.g., leveling, mirror alignment), since this would allow calculating the coordinate system for steering the laser beams that can compensate for pointing errors (see p. 105, Vasiljević, 2014b). Mapping hard targets in several instances during the field study would provide means to update the compensating coordinate system.

The methodology for atmospheric multi-Doppler lidar experiments was applied in the pilot study Perdigão 2015, which serves as an introductory campaign to more extensive and longer planned field studies within the NEWA project. In this field campaign, the long-range and short-range WindScanner systems were used simultaneously for the first time. Also, it was the first time that these instruments were deployed in a challenging site. Over a short period of time, both systems were installed at the designated locations. The 

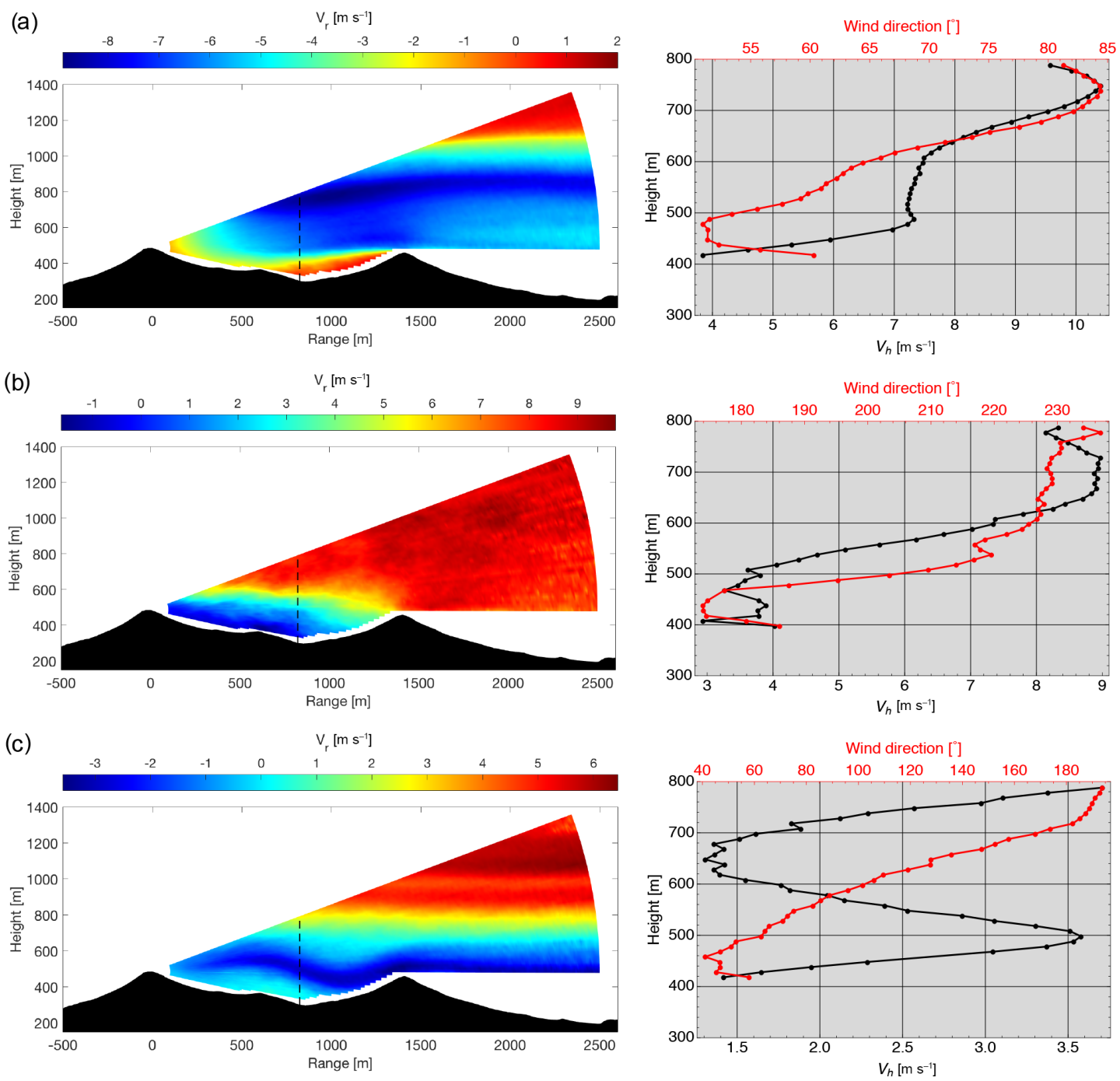

Figure 14. Radial flow fields (10 min averaged) in a vertical plane (left figures) and corresponding virtual mast measurements of the horizontal wind speed and wind direction (right figures) acquired using the transect scan performed by the long-range WindScanner system: (a) northeast dominant wind, recirculation zone on the north ridge (measurements were taken on 7 June 2015 from 03:19 to 03:29 UTC); (b) southwest dominant wind, recirculation zone on the south ridge (measurements were taken on 10 June 2015 from 13:33 to 13:43 UTC); (c) northeast dominant wind, atmospheric internal wave (measurements taken on 10 June 2015 from 03:32 to 03:42 UTC). Negative and positive radial wind speeds indicate winds going towards and away from the lidar, the black and red solid curves correspond to the horizontal wind speed and wind direction, and the dashed black line indicates a position of the virtual met mast. Note that the color pattern of the radial velocity field (left) is not the same in every figure.

established WindScanner calibration and configuration procedures, which were previously used in flat terrain, were successfully applied in the heavily complex terrain of Serra do Perdigão. A pointing accuracy of $0.05^{\circ}$ and a high level synchronization among WindScanners was achieved. Also, two long-range WindScanners on the north ridge were powered by diesel generators without interruptions during their operation.

An important step has been made towards the coupling of the long-range and short-range WindScanner systems into a hybrid WindScanner system. Namely, the scanning strategies were designed and implemented in such a way as to achieve a symbiosis of the two WindScanner systems. However, in this first attempt to realize a hybrid WindScanner system, we can report that we managed to simultaneously operate a hybrid WindScanner system for several hours. A longer operation was hindered by the issues earlier mentioned in Sect. 4.8. The coinciding measurement periods will be thoroughly addressed in forthcoming publications. An obvious focus of future campaigns with a hybrid WindScanner system will be to achieve a full synergy between the long- and short-range 
(a)

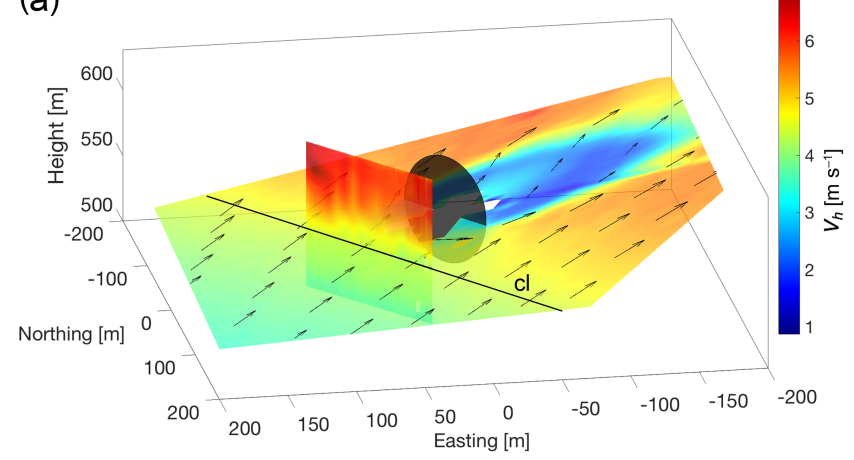

(b) $\quad-\mathrm{SR}(66 \mathrm{~m})-\mathrm{SR}(70 \mathrm{~m})-\mathrm{SR}(74 \mathrm{~m})-\mathrm{LR}(71 \mathrm{~m})$

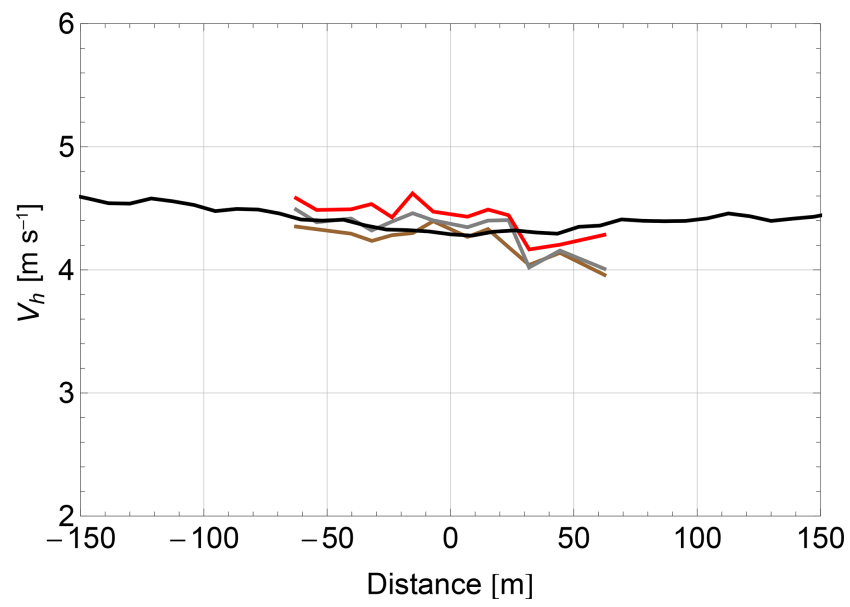

Figure 15. Inflow conditions (10 min averaged) measured by a hybrid WindScanner system on 3 June 2016 from 07:30 to 07:40 UTC: (a) three-dimensional representation of two scanned plane (vertical plane - SRWS, horizontal plane - LRWS) with a black line denoted cl representing the line where the planes intersection coincides; (b) the comparison of horizontal wind speed measured by the short-range WindScanner system (lines denoted by SR) and long-range WindScanner system (line denoted by LR) at points distributed along several horizontal lines (lines at 66, 70, 71 and $74 \mathrm{~m}$ a.g.1.) which are closest to the planes intersection denoted $\mathrm{cl}$ in the upper figure.

WindScanner systems, thus to acquire longer simultaneous measurements of flow fields.

Despite the environmental conditions, challenges imposed by the site and technical issues with the instruments, highquality observations of the various flow aspects of the Perdigão site have been acquired, with a few highlights outlined in this paper. Also, the datasets and presented methodology have been used for the design of a longer and, instrumentation-wise, more extensive Perdigão-2017 field campaign, which took place in the first half of 2017 over a period of 6 months (Witze, 2017; Fernando et al., 2017). In addition to the Perdigão 2015 and Perdigão 2017 experiments, the methodology has been successfully applied in several ex- periments, such as the Kassel-2016 and RUNE campaigns (Floors et al., 2016).

\section{Conclusions}

The methodology for atmospheric multi-Doppler lidar experiments was developed and applied to the Perdigão-2015 field campaign. We described the 10 steps which constitute the methodology and explained how each step was implemented in the field campaign. The application of the steps resulted in a high pointing accuracy and temporal synchronization of the WindScanners. Five novel scanning modes were designed, three in the case of the long-range and two in the case of the short-range WindScanner system, with the purpose of characterizing the overall flow pattern over the double-ridge site. Each scanning mode followed a specific purpose, disclosing a particular aspect of the flow. Because the larger area was covered by the WindScanner measurements in comparison to the standard tower based anemometry, a more detailed view of the atmospheric flow was possible, which increased our understanding of the interplay between the large synoptic scales associated with the weather conditions and the site. An important step was made towards the realization of a hybrid WindScanner system, based on both pulsed and CW lidar technology. Overall, the methodology and its application lay out the foundations for much larger future endeavors that will take place within the NEWA project.

Data availability. The datasets presented in this paper are currently under conversion to the format which will make them simpler for sharing and reuse. They will be accessible throughout the web page (URL): http://e-windlidar.windenergy.dtu.dk/perdigao2015/. 


\section{Appendix A: Wind vector retrieval}

Based on the meteorological convention, the wind vector is defined by the three velocity components:

$\boldsymbol{V}_{\text {wind }}=(u, v, w)$,

where $u$ is the zonal velocity (i.e., component of the horizontal wind towards the east); $v$ is the meridional velocity (i.e., component of the horizontal wind towards the north); and $w$ is the vertical velocity, which is positive for an upward motion.

The LOS or radial speed, $v_{\mathrm{LOS}}$, measured by a lidar represents a projection of the wind vector $\boldsymbol{V}_{\text {wind }}$ on the laser light propagation path:

$v_{\text {LOS }}=\boldsymbol{n} \cdot \boldsymbol{V}_{\text {wind }}=\left(\begin{array}{c}\sin (\theta) \cos (\varphi) \\ \cos (\theta) \cos (\varphi) \\ \sin (\varphi)\end{array}\right) \cdot\left(\begin{array}{c}u \\ v \\ w\end{array}\right)$,

where $\boldsymbol{n}$ is a unit vector describing the direction of the laser light propagation expressed in terms of the azimuth angle $\theta$ and elevation angle $\varphi$.

By measuring three independent radial velocities ( $v_{\mathrm{LOS} 1}$, $v_{\mathrm{LOS} 2}$ and $v_{\mathrm{LOS} 3}$ ) we can retrieve (triple-Doppler retrieval) all three components of the wind vector:

$$
\begin{aligned}
& \left(\begin{array}{c}
u \\
v \\
w
\end{array}\right)= \\
& \left(\begin{array}{lll}
\sin \left(\theta_{1}\right) \cos \left(\varphi_{1}\right) & \cos \left(\theta_{1}\right) \cos \left(\varphi_{1}\right) & \sin \left(\varphi_{1}\right) \\
\sin \left(\theta_{2}\right) \cos \left(\varphi_{2}\right) & \cos \left(\theta_{2}\right) \cos \left(\varphi_{2}\right) & \sin \left(\varphi_{2}\right) \\
\sin \left(\theta_{3}\right) \cos \left(\varphi_{3}\right) & \cos \left(\theta_{3}\right) \cos \left(\varphi_{3}\right) & \sin \left(\varphi_{3}\right)
\end{array}\right) \\
& \cdot\left(\begin{array}{l}
v_{\text {LOS } 1} \\
v_{\text {LOS } 2} \\
v_{\text {LOS } 3}
\end{array}\right) .
\end{aligned}
$$

If the elevation angle is low (e.g., $\varphi<5^{\circ}$ ) and vertical velocity is low (e.g., $<2 \mathrm{~m} \mathrm{~s}^{-1}$ ) then Eq. (A2) can be reduced to

$v_{\mathrm{LOS}}=\left(\begin{array}{l}u \\ v\end{array}\right) \cdot\left(\begin{array}{c}\sin (\theta) \\ \cos (\theta)\end{array}\right)$

since

$\cos \left(5^{\circ}\right)=0.996$

$\sin \left(5^{\circ}\right)=0.087$.

Therefore, the radial velocity can be treated as the projection of the horizontal components of the wind vector on the laser light propagation path. Accordingly, by measuring two independent radial velocities (dual-Doppler retrieval) with laser beams directed at low elevation angles, the horizontal components of the wind vector can be retrieved:

$$
\begin{gathered}
\left(\begin{array}{l}
u \\
v
\end{array}\right)=\left(\begin{array}{ll}
\sin \left(\theta_{1}\right) \cos \left(\varphi_{1}\right) & \cos \left(\theta_{1}\right) \cos \left(\varphi_{1}\right) \\
\sin \left(\theta_{2}\right) \cos \left(\varphi_{2}\right) & \cos \left(\theta_{2}\right) \cos \left(\varphi_{2}\right)
\end{array}\right) \\
\cdot\left(\begin{array}{l}
v_{\mathrm{LOS} 1} \\
v_{\mathrm{LOS} 2}
\end{array}\right) .
\end{gathered}
$$


Competing interests. The authors declare that they have no conflict of interest.

Acknowledgements. The authors are grateful to the following institutions, without which the Perdigão-2015 field campaign would have not been possible. The municipality of Vila Velha de Ródão was extremely useful and always available to answer all our requests, providing solutions to many simple and practical aspects of the experiment that otherwise would have been insurmountable difficulties. We thank Generg for collaboration and support in the field experiment, namely providing power and data connection and for making the wind turbine SCADA data available. We thank the Portuguese Institute for Sea and Atmosphere (IPMA) for the daily forecasts. We also thank Regacentro Comércio de Representações Lda for the ingenious solution that enabled off-grid power to two scanning lidars in remote locations. Particularly, we would like to express special gratitude to Per Hansen and Claus Pedersen from DTU Wind Energy for their dedicated work and positive spirit during the experiment deployment and execution. We are grateful to the FarmOpt, UniTTe, NEWA and WindScanner.eu projects for the financial support of the Perdigão-2015 field campaign. FarmOpt (http://energiforskning.dk/en/projects/detail? program $=$ All\&teknologi $=$ All\&field_bevillingsaar_value $=\&$ start $=$ $\&$ slut $=\&$ field_status_value $=$ All \&keyword=FarmOpt\&page $=0$ ) was funded by the Danish Energy Technology Development and Demonstration Program (EUDP), project no. 64013-0405. UniTTe (http://www.unitte.dk/) is financially supported by the Danish Innovation Fund (Innovationsfonden), grant no. 130500024A. NEWA (http://www.neweuropeanwindatlas.eu/) is an ERANET + project, which is funded by the European Commission (ENER/FP7/618122/NEWA) and nine national funding agencies. WindScanner.eu (http://www.windscanner.eu) was funded by the European Commission under the FP7-INFRASTRUCTURES call, project no. 312372. The first author would like to express gratitude to the IRPWind mobility program (http://www.irpwind.eu/), which provided the financial support for his stay in Portugal during the Perdigão-2015 field campaign. Finally, all authors would like to express gratitude to two anonymous referees and Raghu Krishnamurthy (Notre Dame University) for their constructive comments and feedbacks which improved the quality of this paper.

Edited by: Ad Stoffelen

Reviewed by: two anonymous referees

\section{References}

Berg, J., Vasiljević, N., Kelly, M., Lea, G., and Courtney, M.: Addressing Spatial Variability of Surface-Layer Wind with LongRange WindScanners, J. Atmos. Ocean. Tech., 32, 518-527, https://doi.org/10.1175/JTECH-D-14-00123.1, 2015.

Bingöl, F., Mann, J., and Foussekis, D.: Conically scanning lidar error in complex terrain, Meteorol. Z., 18, 189-195, 2009.

Browning, K. A. and Wexler, R.: The Determination of Kinematic Properties of a Wind Field Using Doppler Radar, J. Appl. Meteorol., 7, 105-113, 1968.

Cariou, J.-P. and Boquet, M.: Leosphere Pulsed Lidar Principles, Tech. rep., UpWind, 2011.
Castro, F. A., Palma, J. M. L. M., and Lopes, A. S.: Simulation of the Askervein Flow. Part 1: Reynolds Averaged Navier-Stokes Equations $(k-\varepsilon$ Turbulence Model), Bound.-Lay. Meteorol., 107, 501-530, https://doi.org/10.1023/A:1022818327584, 2003.

Collier, C. G., Davies, F., Bozier, K. E., Holt, A. R., Middleton, D. R., Pearson, G. N., Siemen, S., Willetts, D. V., Upton, G. J. G., and Young, R. I.: Dual-Doppler Lidar Measurements for Improving Dispersion Models, B. Am. Meteorol. Soc., 86, 825838, 2005.

Courtney, M., Wagner, R., and Lindelöw, P.: Testing and comparison of lidars for profile and turbulence measurements in wind energy, IOP Conference Series: Earth and Environmental Science, 1, U172-U185, 2008.

Debnath, M., Iungo, G. V., Ashton, R., Brewer, W. A., Choukulkar, A., Delgado, R., Lundquist, J. K., Shaw, W. J., Wilczak, J. M., and Wolfe, D.: Vertical profiles of the 3-D wind velocity retrieved from multiple wind lidars performing triple range-height-indicator scans, Atmos. Meas. Tech., 10, 431-444, https://doi.org/10.5194/amt-10-431-2017, 2017.

Delta Tau: Motion and Control Ring Optical Ring, available at: http: //www.macro.org, last access: 5 September 2017.

EUREF: European Terrestrial Reference System 89 (ETRS89), available at: http://etrs89.ensg.ign.fr (last access: 5 September 2017), 2016.

EWEA: Prioritising Wind Energy Research: Strategic Research Agenda of the Wind Energy Sector, Tech. rep., EWEA-European Wind Energy Association, 2005.

EWEA: Strategic Research Agenda and Market Deployment Strategy, From 2008 to 2030, Tech. rep., TPWind European Wind Energy Technology Platform/European Wind Energy Association, 2008.

Fernando, H., Lundquist, J., and Oncley, S.: Monitoring wind in Portugal's mountains down to microscales, EOS, 98, https://doi.org/10.1029/2017EO074745, 2017.

Floors, R., Peña, A., Lea, G., Vasiljević, N., Simon, E., and Courtney, M.: The RUNE Experiment - A Database of RemoteSensing Observations of Near-Shore Winds, Remote Sensing, 8, 2016.

Fuertes, F. C., Iungo, G. V., and Porté-Agel, F.: 3D Turbulence Measurements Using Three Synchronous Wind Lidars: Validation against Sonic Anemometry, J. Atmos. Ocean. Tech., 31, 15491556, https://doi.org/10.1175/JTECH-D-13-00206.1, 2014.

Gomes, V.: The Wind Flow over Serra do Perdigão. Computational preliminary studies, Tech. Rep. CESA2010.VCG03.A, CEsA Centre for Wind Energy and Atmospheric Flows, Faculdade de Engenharia da Universidade do Porto, Rua Dr Roberto Frias s/n, 4200-465 Porto, Portugal, 2011.

Grubišić, V., Doyle, J. D., Kuettner, J., Dirks, R., Cohn, S. A., Pan, L. L., Mobbs, S., Smith, R. B., Whiteman, C. D., Czyzyk, S., Vosper, S., Weissmann, M., Haimov, S., Wekker, S. F. J. D., and Chow, F. K.: The Terrain-Induced Rotor Experiment, B. Am. Meteorol. Soc., 89, 1513-1533, https://doi.org/10.1175/2008BAMS2487.1, 2008.

Hansen, K., Larsen, G., Menke, R., Vasiljević, N., Angelou, N., Feng, J., Zhu, W., Vignaroli, A., Liu, W., Xu, C., and Shen, W.: Wind turbine wake measurement in complex terrain, Journal of Physics: Conference Series, 753, 032013, available at: http://stacks.iop.org/1742-6596/753/i=3/a=032013 (last access: 5 September 2017), 2016. 
Immas, A., Kluczewska-Bordier, J., Beneditti, P., Pitance, D., Horb, S., Parneix, N., Silvert, F., Deglaire, P., de Jouette, C., Sjöholm, M., Angelou, N., Hansen, K., and Mikkelsen, T.: Study of largescale vertical axis wind turbine wake through numerical modelling and fullscale experiments, in: EWEA Annual Conference and Exhibition 2015, Paris, France, 2015.

INEGI: Perdigão's Wind Farm, Wind farm study, INEGI, 2005 (in Portuguese).

Iungo, G. V., Wu, Y.-T., and Porté-Agel, F.: Field Measurements of Wind Turbine Wakes with Lidars, J. Atmos. Ocean. Tech., 30, 274-287, https://doi.org/10.1175/JTECH-D-12-00051.1, 2013.

Jackson, P. S. and Hunt, J. C. R.: Turbulent wind flow over a low hill, Q. J. Roy. Meteorol. Soc., 101, 929-955, https://doi.org/10.1002/qj.49710143015, 1975.

Lange, J., Mann, J., Angelou, N., Berg, J., Sjöholm, M., and Mikkelsen, T.: Variations of the Wake Height over the Bolund Escarpment Measured by a Scanning Lidar, Bound.-Lay. Meteorol., 159, 147-159, https://doi.org/10.1007/s10546-015-0107-8, 2016.

Lundquist, J. K., Wilczak, J. M., Ashton, R., Bianco, L., Brewer, W. A., Choukulkar, A., Clifton, A., Debnath, M., Delgado, R., Friedrich, K., Gunter, S., Hamidi, A., Iungo, G. V., Kaushik, A., Kosović, B., Langan, P., Lass, A., Lavin, E., Lee, J. C.-Y., McCaffrey, K. L., Newsom, R. K., Noone, D. C., Oncley, S. P., Quelet, P. T., Sandberg, S. P., Schroeder, J. L., Shaw, W. J., Sparling, L., Martin, C. S., Pe, A. S., Strobach, E., Tay, K., Vanderwende, B. J., Weickmann, A., Wolfe, D., and Worsnop, R.: Assessing State-of-the-Art Capabilities for Probing the Atmospheric Boundary Layer: The XPIA Field Campaign, B. Am. Meteorol. Soc., 98, 289-314, https://doi.org/10.1175/BAMS-D15-00151.1, 2017.

Mann, J., Cariou, J.-P., Courtney, M. S., Parmentier, R., Mikkelsen, T., Wagner, R., Lindelöw, P., Sjöholm, M., and Enevoldsen, K.: Comparison of 3D turbulence measurements using three staring wind lidars and a sonic anemometer, Meteorol. Z., 18, 135-140, 2009.

Mann, J., Palma, J., Matos, J. C., Angelou, N., Courtney, M., Lea, G., and Vasiljević, N.: Experimental investigation of flow over a double ridge with several Doppler lidar systems, in: 96th American Meteorological Society Annual Meeting, January 2016, New Orleans, LA, available at: https://ams.confex.com/ams/ 96Annual/webprogram/Paper284781.html, recorded presentation at https://ams.confex.com/ams/96Annual/videogateway.cgi/ $\mathrm{id} / 31860$ ?recordingid $=31860$ \&uniqueid=Paper284781\&entry_ password=858263 (last access: 5 September 2017), 2016.

Mann, J., Angelou, N., Arnqvist, J., Callies, D., Cantero, E., Arroyo, R. C., Courtney, M., Cuxart, J., Dellwik, E., Gottschall, J., Ivanell, S., Kühn, P., Lea, G., Matos, J. C., Palma, J. M. L. M., Pauscher, L., Peña, A., Rodrigo, J. S., Söderberg, S., Vasiljevic, N., and Rodrigues, C. V.: Complex terrain experiments in the New European Wind Atlas, Philos. T. R. Soc. Lond. A, 375, 2091, https://doi.org/10.1098/rsta.2016.0101, 2017.

McCarthy, J., Wilson, J. W., and Fujita, T. T.: The Joint Airport Weather Studies Project, B. Am. Meteorol. Soc., 63, p. 15, 1982.

Meyer Forsting, A., Troldborg, N., Bechmann, A., Angelou, N., and Vasiljević, N.: Validation of a CFD model with a triplelidar system upstream of a wind turbine in complex terrain, in: ECCOMAS Congress 2016, Hersonissos (Greece), 5-10 June, available at: http://orbit.dtu.dk/files/124220216/Eccomas2016. pdf (last access: 5 September 2017), 2016.

Mikkelsen, T.: Lidar-based Research and Innovation at DTU Wind Energy - a Review, Journal of Physics: Conference Series, 524, 012007, available at: http://stacks.iop.org/1742-6596/524/i=1/a= 012007 (last access: 5 September 2017), 2014.

Mikkelsen, T., Mann, J., and Nielsen, M.: Rotating prism scanning device and method for scanning, EP 2304489, 2011.

Mortensen, N. G., Landberg, L., Troen, I., Petersen, E. L., Rathmann, O., and Nielsen, M.: WAsP Utility Programs, Tech. Rep. Ris $\varnothing-R-995(E N)$, Ris $\varnothing$ National Laboratory, Roskilde, Denmark, available at: http://orbit.dtu.dk/files/106312446/ris_i_2261.pdf (last access: 5 September 2017), 2004.

Newman, J. F., Bonin, T. A., Klein, P. M., Wharton, S., and Newsom, R. K.: Testing and validation of multi-lidar scanning strategies for wind energy applications, Wind Energy, 19, 2239-2254, https://doi.org/10.1002/we.1978, 2016.

Newsom, R., Ligon, D., Calhoun, R., Heap, R., Cregan, E., and Princevac, M.: Retrieval of Microscale Wind and Temperature Fields from Single- and Dual-Doppler Lidar Data, J. Appl. Meteorol., 44, 1324-1345, https://doi.org/10.1175/JAM2280.1, 2005.

Newsom, R. K., Berg, L. K., Shaw, W. J., and Fischer, M. L.: Turbine-scale wind field measurements using dual-Doppler lidar, Wind Energy, 18, 219-235, https://doi.org/10.1002/we.1691, 2015.

Palma, J., Castro, F., Ribeiro, L., Rodrigues, A., and Pinto, A.: Linear and nonlinear models in wind resource assessment and wind turbine micro-siting in complex terrain, J. Wind Eng. Ind. Aerod., 96, 2308-2326, https://doi.org/10.1016/j.jweia.2008.03.012, 2008.

Pauscher, L., Vasiljević, N., Callies, D., Lea, G., Mann, J., Klaas, T., Hieronimus, J., Gottschall, J., Schwesig, A., Kühn, M., and Courtney, M.: An Inter-Comparison Study of Multi- and DBS Lidar Measurements in Complex Terrain, Remote Sensing, 8, 782, https://doi.org/10.3390/rs8090782, 2016.

Peña Diaz, A., Hasager, C., Gryning, S.-E., Courtney, M., Antoniou, I., and Mikkelsen, T.: Offshore wind profiling using light detection and ranging measurements, Wind Energy, 12, 105-124, 2009.

Rodrigues, C. V., Palma, J., Vasiljević, N., Courtney, M., and Mann, J.: Coupled simulations and comparison with multilidar measurements of the wind flow over a double-ridge, Journal of Physics: Conference Series, 753, 032025, available at: http://stacks.iop.org/1742-6596/753/i=3/a=032025 (last access: 5 September 2017), 2016.

Shaw, W. J., Lundquist, J. K., and Schreck, S. J.: Research Needs For Wind Resource Characterization, B. Am. Meteorol. Soc., 90, 535-538, https://doi.org/10.1175/2008BAMS2729.1, 2009.

Simley, E., Angelou, N., Mikkelsen, T., Sjöholm, M., Mann, J., and Pao, L. Y.: Characterization of wind velocities in the upstream induction zone of a wind turbine using scanning continuous-wave lidars, Journal of Renewable and Sustainable Energy, 8, 013301, https://doi.org/10.1063/1.4940025, 2016.

Sjöholm, M., Angelou, N., Hansen, P., Hansen, K. H., Mikkelsen, T., Haga, S., Silgjerd, J. A., and Starsmore, N.: Two-Dimensional Rotorcraft Downwash Flow Field Measurements by LidarBased Wind Scanners with Agile Beam Steering, J. Atmos. Ocean. Tech., 31, 930-937, https://doi.org/10.1175/JTECH-D13-00010.1, 2014. 
Strauch, R. G., Weber, B. L., Frisch, A. S., Little, C. G., Merritt, D. A., Moran, K. P., and Welsh, D. C.: The Precision and Relative Accuracy of Profiler Wind Measurements, J. Atmos. Ocean. Tech., 4, 563-571, 1987.

Taylor, P., Mason, P., and Bradley, E.: Boundary-layer flow over low hills, Bound.-Lay. Meteorol., 39, 107-132, 1987.

Taylor, P. A. and Teunissen, H. W.: The Askervein Hill project: Overview and background data, Bound.-Lay. Meteorol., 39, 1539, https://doi.org/10.1007/BF00121863, 1987.

van Kuik, G. A. M., Peinke, J., Nijssen, R., Lekou, D., Mann, J., Sørensen, J. N., Ferreira, C., van Wingerden, J. W., Schlipf, D., Gebraad, P., Polinder, H., Abrahamsen, A., van Bussel, G. J. W., Sørensen, J. D., Tavner, P., Bottasso, C. L., Muskulus, M., Matha, D., Lindeboom, H. J., Degraer, S., Kramer, O., Lehnhoff, S., Sonnenschein, M., Sørensen, P. E., Künneke, R. W., Morthorst, P. E., and Skytte, K.: Long-term research challenges in wind energy - a research agenda by the European Academy of Wind Energy, Wind Energ. Sci., 1, 1-39, https://doi.org/10.5194/wes1-1-2016, 2016.

Vasiljević, N.: Flickr photo gallery of Perdigão 2014 site visit, available at: https://www.flickr.com/photos/zamjatin/sets/ 72157649022069345 (last access: 5 September 2017), 2014a.

Vasiljević, N.: A time-space synchronization of coherent Doppler scanning lidars for 3D measurements of wind fields, $\mathrm{PhD}$ thesis, Technical University of Denmark (DTU), phD-0027, 2014b.

Vasiljević, N.: Perdigão-2015 blog, available at: https: //perdigao-2015.tumblr.com (last access: 5 September 2017), 2015a.

Vasiljević, N.: WindScanner installation video, available at: https://www.youtube.com/watch? $\mathrm{v}=$ hsiZ9W4VHwo (last access: 5 September 2017), 2015 b.

Vasiljević, N.: Diamond scan animation, available at: https://www. youtube.com/watch? $\mathrm{v}=\mathrm{g} 9$ brbIXK7F8 (last access: 5 September 2017), 2016a.

Vasiljević, N.: Diamond scan $24 \mathrm{H}$ results, available at: https://www.youtube.com/watch?v=5uMdanEQ_2A (last access: 5 September 2017), 2016b.
Vasiljević, N.: Ridge scan animation, available at: https://www. youtube.com/watch?v=CvnJAev69J0 (last access: 5 September 2017), 2016c.

Vasiljević, N.: Transect scan animation, available at: https://www. youtube.com/watch?v=RmLtkP2-KS4 (last access: 5 September 2017), 2016d.

Vasiljević, N.: Transect scan $24 \mathrm{H}$ results, available at: https://www. youtube.com/watch?v=jaNFvtDdhQI (last access: 5 September 2017), 2016e.

Vasiljević, N. and Courtney, M.: Accuracy of dual-Doppler lidar retrievals of near-shore winds, in: WindEurope Resource Assessment Workshop, March 2017, Edinburgh, United Kingdom, available at: http://orbit.dtu.dk/files/131412313/Submitted_ Vasiljevic.pptx, last access: 5 September 2017.

Vasiljević, N., Courtney, M., Wagner, R., Mann, J., and Mikkelsen, T.: A windscanner simulator, in: EWEC 2011, Bruxelles (Belgium), 14-17 March, available at: http://orbit.dtu.dk/files/ 5497505/Vasiljevic_poster_EWEA2011presentation.pdf (last access: 5 September 2017), 2011.

Vasiljević, N., Lea, G., Courtney, M., Cariou, J.-P., Mann, J., and Mikkelsen, T.: Long-Range WindScanner System, Remote Sensing, 8, 896, https://doi.org/10.3390/rs8110896, 2016a.

Vasiljević, N., Lea, G., Hansen, P., and Jensen, H.: Mobile network architecture of the long-range WindScanner system, Tech. Rep. E-0105, DTU Wind Energy, Roskilde, Denmark, available at: http://orbit.dtu.dk/files/120566712/Mobile_ network_architecture.pdf, 2016b.

Walmsley, J. L. and Taylor, P. A.: Boundary-layer flow over topography: Impacts of the Askervein study, Bound.-Lay. Meteorol., 78, 291-320, 1996.

Walmsley, J. L., Taylor, P. A., and Keith, T.: A simple model of neutrally stratified boundary-layer flow over complex terrain with surface roughness modulation (MS3DJH/3R), Bound.-Lay. Meteorol., 36, 157-186, 1986.

Witze, A.: World's largest wind-mapping project spins up in Portugal, Nature, 542, 282-283, 2017. 